\title{
Finite Difference Modeling of Rotor Flows Including Wake Effects
}

\section{F. X. Caradonna, A. Desopper, and C. Tung}

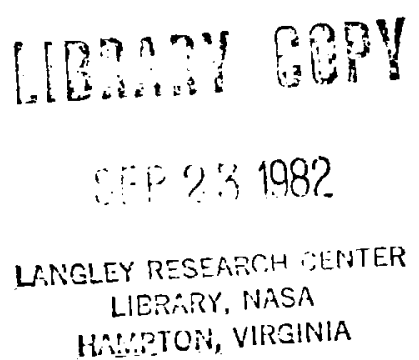





\section{EUTER:}

OISPLAY 2421

82N3334\% ISSUE 24 PAGE 3384 CATEGORY 2 RPT: MASA-TM-84280

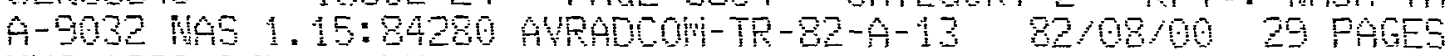
UMCLASEIFIED DOOUAENT

UTIL: Finte diference modeline of poto flows including whe effecte

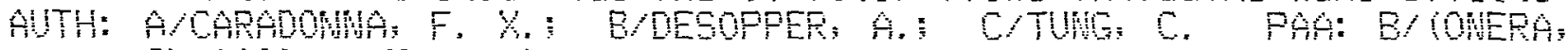
Chatillon Francel

Core: Wationel Aeronautics and Snace Administration. Ames Resarch conter; Moffett Field; Calif.; Amy Research and Techology Labs.; Moffett Field; Callf. AMIL.NTIS GAP: HC AOS/MF AOI

Prepared in cooperation with Army Resentoh End Technology Labs.; Moffett Field; Calif.

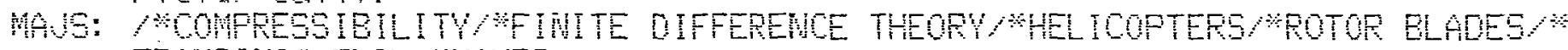
TRAMCOMIC FLOU MHAKS

MIMS: AMGL OF GTTAK BOUNARY LAYER CONTROL PARTIAL DIFFERETIAL EOUATIONS

ABA: F. F.

ABs: Rotary wing finte differeno methode are investideted. The man co 


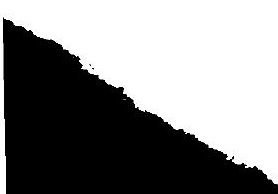




\section{Finite Difference Modeling of Rotor Flows Including Wake Effects}

F. X. Caradonna, Aeromechanics Laboratory, AVRADCOM Research and Technology Laboratories Ames Research Center, Moffett Field, California

A. Desopper, Office National D'etudes et de Recherches Aerospatiales, Chatillon, France C. Tung, Aeromechanics Laboratory, AVRADCOM Research and Technology Laboratories Ames Research Center, Moffett Field, California

United States Army Áviation Research and Ames Research Center Moffett Field, California 94035
Development Command

St. Louis, Missouri 63166

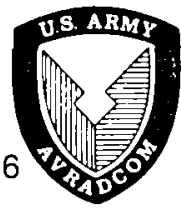




\author{
F. X. Caradonna* \\ A. Desopper** \\ C. Tung* \\ *U.S. Army Aeromechanics Laboratory, AVRADCOM \\ Ames Research Center, Moffett Field, California \\ **office National $D^{\prime}$ etudes et de Recherches Aerospatiales \\ Chatillon, France
}

\title{
SUMMARY
}

This paper gives a brief consideration of rotary wing finite difference methods. The main concern is the specification of boundary conditions to properly account for the effect of the wake on the blade. Examples are given of an approach where wake effects are introduced by specifying an equivalent angle of attack. An alternate approach is also given where discrete vortices are introduced into the finite difference grid. The resulting computations of hovering and high advance-ratio cases compare well with experiment. Some consideration is also given to the modeling of low-to-moderate advance-ratio flows.

\section{LIST OF SYMBOLS}

$$
\begin{aligned}
& \mathrm{A}=\mathrm{M}^{2} / \delta^{2 / 3} \mathrm{AR}^{2} \\
& \mathrm{AR}=\mathrm{R} / \mathrm{C} \text {, aspect ratio } \\
& \mathrm{B}=2 \mathrm{M}^{2} \mathrm{f} / \mathrm{AR}^{2 / 3} \\
& \mathrm{C}=1 / \mathrm{AR}^{2} \delta^{2 / 3} \\
& \mathrm{C}=\text { chord } \\
& \mathrm{C}_{\mathrm{P}}=\text { pressure coefficient } \\
& \mathrm{C}_{\mathrm{P}}^{*}=\text { critica1 pressure coefficient } \\
& \mathrm{C}_{\mathrm{T}}=\mathrm{thrust} \text { coefficient } \\
& \mathrm{D}=\mathrm{Bg} \\
& \mathrm{F}=\frac{1-\mathrm{f}^{2} \mathrm{M}^{2}}{\delta^{2} / 3} \phi_{\mathrm{X}}-\mathrm{M}^{2}\left[\left(\frac{\gamma+1}{2}\right) \mathrm{f}_{\mathrm{X}}+\frac{(\gamma-1)}{\mathrm{AR}} \phi_{\mathrm{t}}\right] \phi_{\mathrm{X}} \\
& \mathrm{f}=\mathrm{y}+\mu \text { sin } \Omega \mathrm{t} \\
& \mathrm{g}=\mathrm{x}-\mu \cos \Omega \mathrm{t} \\
& \mathrm{M}=\mathrm{Mach} \text { number }
\end{aligned}
$$




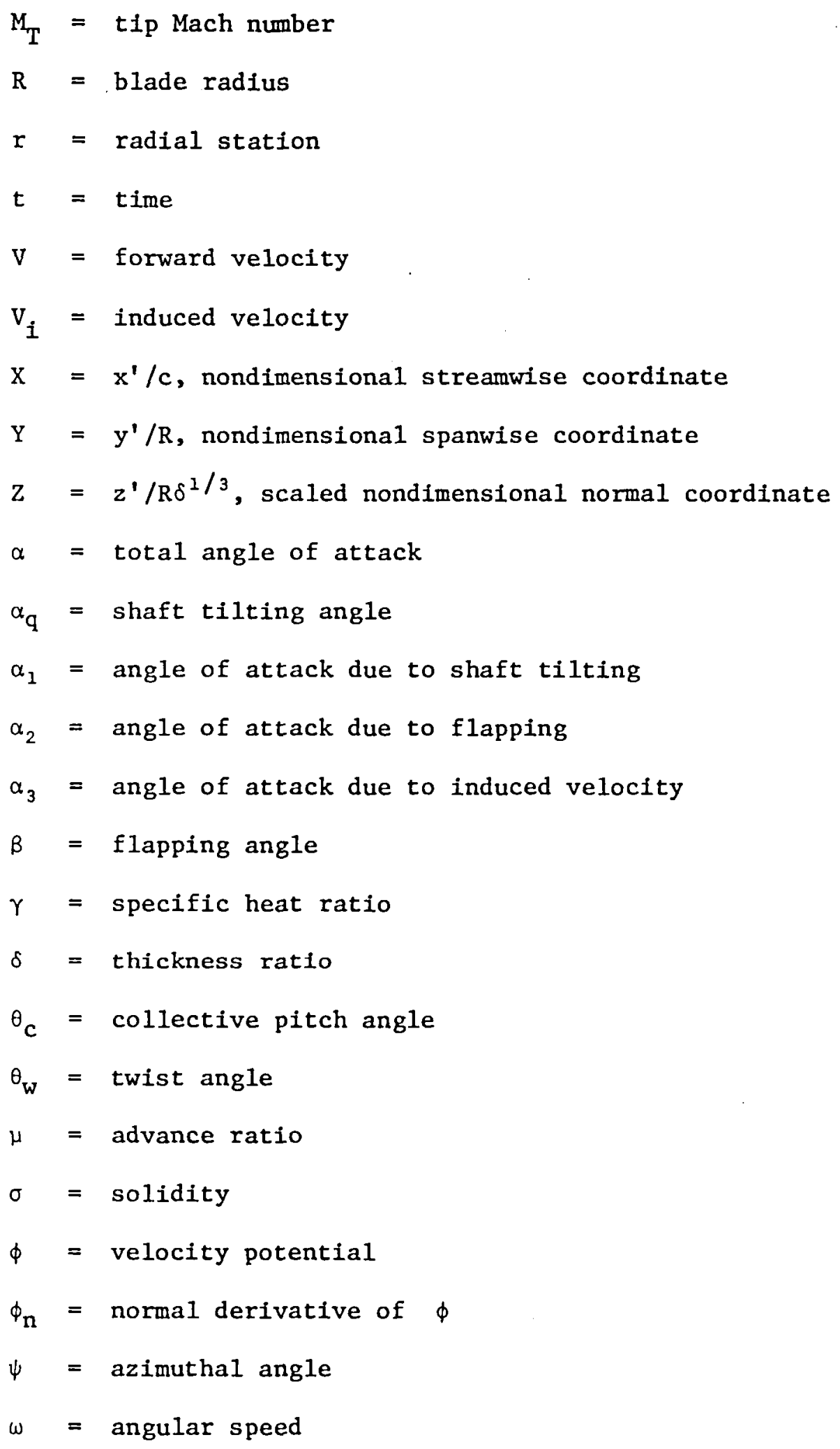




\section{Introduction}

The aerodynamic prediction tools available for routine rotor flow prediction and design have been limited to the simplest methods by the cost of computation. However, current rapid decreases in the cost of computation are enabling a quiet, but fundamental reappraisal of our flow-prediction methodology. At present, integral methods (i.e., panel or lifting surface) with prescribed wakes are the most comprehensive methods being used in a routine fashion. However, these met? those associated with transonic flows. The best current means of treating such problems is with finite difference methods (FDM).

The essence of the FDM approach is to use Taylor series expansions to approximate the partial differential equations by difference equations, which are then solved by implementing a variety of matrix methods. The method solves the flow region at a finite number of grid points. Proper flow resolution depends on placing a sufficient number of grid points at all significant flow regions. Unfortunately, a typical real rotor flow often contains so many important flow regions (the blade, the wake system, and the fuselage and acoustic propagation regions) that totally self-contained FDM solutions of complete rotor flows is not likely within the next five years. However, practical rotor loads, performance, and design work using FDM may be accomplished using isolated blade computations, if we know how to properly specify our boundary conditions. The intent of this paper is to demonstrate various types of boundary condition specifications to perform FDM computations of various rotor flow conditions. For convenience, a small-disturbance potential equation will be used for this modeling.

\section{Equation of Motion and Boundary Conditions}

The simplest model equation which encompasses transonic flow effects is the classical transonic small-disturbance equation, which for a rotor has the form,

$$
A \phi_{t t}+B \phi_{x t}=F_{x}+\phi_{z z}+C \phi_{y y}+D \phi_{x y}
$$

where $F$ is a nonlinear flux term and is a function of $\phi_{X}$ and $\phi_{t}$. This equation was derived under the assumption of small thickness and crossflow and high Mach number [1]. By the means of various mixed difference schemes, Eq. (1) has been shown to give good transonic solutions for unswept, nonlifting rotors for advance ratios as high as $0.6[2,3]$.

Equation (1) can be solved in three forms. 1) The steady form in which all time-derivative terms are ignored [4]. In this case, high-speed hover solutions have been obtained using a classical relaxation scheme to solve the difference equations. In ref. [4] the effect of the wake was obtained by including one vortex in the solution grid. This gave a solution which bore qualitative resemblance to a hover flow, but the model was too simple to be very accurate. 2) The low-frequency solution in which all unsteady terms except $\phi_{x t}$ are ignored [3]. This approximation is valid for flow variations which occur in several (say, 4) or more chord lengths of blade travel, which includes most rotor phenomena. Nonlifting computations using this model have been made using an alternating direction implicit (ADI) scheme and have compared very well with experimental data. However, good lifting solutions have not yet been obtained due to the lack of inclusion of a downwash model. 3) The fully unsteady case in which all unsteady terms are included. This case includes all high-frequency flows, the most notable of which is that resulting from the near passage of a 
vortex. Perhaps the greatest hindrance to this problem is the lack of suitable experimental data.

In general, Eq. (1) can be solved for simple flows; that is, the physics of compressibility no longer is a problem. However, the physical models required to accurately simulate real rotor flows (by FDM) have not been completely worked out or used. The rotor operates in the vicinity of a complex and often physically close vortex system. Because we can only practically solve for the flow on an isolated blade, the vortex system (as well as other flow features) must be accounted for by a careful specification of the boundary conditions. The simplest possible set of boundary conditions for an isolated lifting rotor must contain the following features (Fig. 1):

1. The surface tangency condition. For the small disturbance equation this consists of equating the upper and lower surface slopes of the blade to the vertical flow component at a mean surface.

2. The trailing vorticity sheet. This is an interior flow boundary condition - a sheet extending rearward from the blade, across which there is a specified potential discontinuity whose strength is the vorticity that has been convected from the trailing edge. This sheet is usually assumed to be undistorted and coincident with a coordinate surface.

3. The far-field boundary condition. The outer boundary surfaces are usually located sufficiently far from the rotor that free-stream conditions $\phi=0$ or $\phi_{n}=0$ can be specified there. It is important that the boundary condition used on an outer surface be compatible with any interior boundary that extends to this surface. For instance, compatibility with the trailing vorticity sheet requires that free-stream pressure be specified on the rear boundary. For a steady flow this corresponds to setting $\phi_{\mathrm{n}}=0$.

4. The inner radial surface boundary. To conserve mesh points, only the outer portion of the rotor flow is computed. Since the inner rotor flow is two dimensional away from the tip, it suffices to use strip theory $\left(i . e ., \phi_{n n}=0\right.$ ) on the inboard computational plane.

Although the above boundary conditions are all that are required for fixed wing work, they are incomplete for the rotor situation because the downwash induced by the wake system is not accounted for (except for that flow induced by the vortex sheet included in the grid). The simplest possible way to include this downwash is to modify the surface tangency condition by prescribing an effective angle of attack. An example of this approach is given in the following section.

3. Computation of High-Speed Advancing Blade Loads. Comparison with Experiment.

An ideal situation in which to employ the angle-of-attack approach is for high advance-ratio flight (say, greater than 0.3 ) where the induced downwash is small. Furthermore, there exists a good body of model blade surface pressure data for this case $[2,3,5]$. This data (obtained at ONERA using 2 and 3 bladed rotors with instrumented removable tips) covers a number of high advance-ratio conditions ranging from nonlifting to moderately loaded $\left(C_{\mathrm{T}} / \sigma \approx 0.06\right)$ cases. Al1 previous computations of these cases have been only for the nonlifting cases using the low-frequency form of Eq. (1). To perform some first computations of the lifting cases, the induced incidence has been calculated using the Drees downwash model [6]. This simple model neglects all discrete blade effects (such 
as the tip vortices) and computes downwash only at the rotor center and $3 / 4$ radius (the downwash elsewhere is taken as a Iinear interpolation or extrapolation from these two points). The simplifications of this model are such that it was not deemed necessary to modify this downwash by the vortex-sheet-induced velocities when it was used in the finite difference code.

The unsteady calculations have been performed on an isolated blade with an angle of attack prescribed along the blade for each azimuthal location by:

$$
\alpha(r / R, \psi)=\theta_{c}+\theta_{w}(r / R-0.7)+\alpha_{1}+\alpha_{2}+\alpha_{3}
$$

with

$$
\begin{aligned}
& \alpha_{1}=\tan ^{-1}\left[V \sin \alpha_{q} \cos \beta /\left(\Omega r+V \cos \alpha_{q} \sin \psi\right)\right] \\
& \left.\alpha_{2}=\tan ^{-1}\left\{\left[-r \Omega(d \beta / d \psi)-V \cos \alpha_{q} \cos \psi \sin \beta\right] /\left(\Omega r+V \cos \alpha_{q} \sin \psi\right)\right]\right\} \\
& \alpha_{3}=\tan ^{-1}\left[-v_{i} \cos \beta /\left(\Omega r+V \cos \alpha_{q} \sin \psi\right)\right]
\end{aligned}
$$

and

$$
v_{i}=v_{i m}+v_{i c} \frac{r}{R} \cos \psi-v_{i s} \frac{r}{R} \sin \psi
$$

where

$$
\begin{aligned}
& \mathrm{v}_{\text {im }}=\frac{1}{1-(3 / 2) \mu_{\mathrm{x}}^{2}} \frac{\mathrm{v}_{\text {io }}^{2}}{\mathrm{~V}_{\mathrm{x}}} \\
& \mathrm{v}_{\text {ic }}=\frac{4}{3} \mathrm{v}_{\mathrm{im}}\left(1-1.8 \mu_{\mathrm{x}}^{2}\right) \\
& \mathrm{v}_{\text {is }}=2 \mu_{\mathrm{x}} \mathrm{V}_{\mathrm{im}} \\
& \mathrm{v}_{\mathrm{io}}^{2}=\frac{\mathrm{C}_{\mathrm{T}}(\Omega \mathrm{R})^{2}}{2} \\
& \mathrm{~V}_{\mathrm{x}}=\mathrm{V}_{\cos \alpha_{\mathrm{q}}} \\
& \mu_{\mathrm{x}}=\frac{\mathrm{V}_{\mathrm{x}}}{\Omega \mathrm{R}}
\end{aligned}
$$

The experimental values are used for the rotor shaft only $\left(\alpha_{q}\right)$, the collective pitch angle $\left(\theta_{c}\right)$, the blade twist angle $\left(\theta_{\mathrm{w}}\right)$, and the flapping angle $(\beta)$. An example showing the evolution and relative magnitude of the different terms: $\theta_{c}+\theta_{w}(r / R-0.7) ; \alpha_{1} ; \alpha_{2} ;$ and $\alpha_{3}$ is given in Fig. 2. It is seen in this figure that although the induced angle is the smallest single contributer to the inflow, it is nevertheless significant in the first quadrant where the other terms nearly cancel each other.

Two experimental cases have been computed corresponding to the following conditions: 
First case:

$$
\mathrm{C}_{\mathrm{T}} / \sigma=0.05, \mathrm{~V}=76 \mathrm{~m} / \mathrm{sec}, \Omega \mathrm{R}=210 \mathrm{~m} / \mathrm{s}
$$

Second case:

$$
\mathrm{C}_{\mathrm{T}} / \sigma=0.0665, \mathrm{~V}=81.4 \mathrm{~m} / \mathrm{s}, \Omega \mathrm{R}=210 \mathrm{~m} / \mathrm{s}
$$

The theoretical pressure distributions for the azimuths $\psi=30^{\circ}, 60^{\circ}, 90^{\circ}$, $120^{\circ}, 150^{\circ}$, and $180^{\circ}$ are compared with the experimental results in Figs. $3-5$ $\left(\mathrm{C}_{\mathrm{T}} / \sigma=0.05\right)$ and Figs. $6-8\left(\mathrm{C}_{\mathrm{T}} / \sigma=0.0665\right)$. The evolution of the pressure distribution is fairly well predicted, including the development of a shock wave for $\psi=90^{\circ}$ and $120^{\circ}$. For the second case, the computed shock wave tends to be stronger and located further aft of the experimentally obtained shock.

In general, the discrepancies between experiment and calculation tend to be greatest in the first quadrant. These differences between experiment and calculation are more easily seen if we display the time history of the pressure coefficient at several points on the blade surface. Such time histories are shown for the spanwise section, $r / R=0.9$, for $C_{T} / \sigma=0.5$, and for 0.665 (Figs. 9 and 10, respectively). The differences seen in the first quadrant are almost certainly a result of inaccuracies in the very simple inflow model. (Recall that the induced velocity is much greater in the first quadrant than in the second.) The most significant error in the second quadrant is in the shock location. This may also be a residual effect of the induced velocity. However, an equally likely possibility is that we are seeing the effects of neglecting the boundary layer. It has been shown, by a number of calculations with boundary layer models included, that the effect of viscosity is to weaken the shock and move it upstream [7].

Overall, the results obtained by these first lifting calculations of the flow around a helicopter blade in forward flight $(\mu>0.3)$ are in good agreement with the experimental results. However, the use of a more sophisticated mode1 for the determination of the induced velocity is certainly necessary for the lower advance ratios.

\section{Lifting-Rotor Computations by Intra-Grid Vortex Insertion. Steady Cases.}

Transonic computations using an angle-of-attack condition cannot be valid when the vortex is too close to the blade surface. This is because the flow nonlinearity demands that the effect of the vortex be computed at all points in the flow, and not just at the blade surface. To handle this situation, one can conceive of solving for the perturbation potential about the vortex-induced velocity field. However, a simpler approach is to modify the existing vortex sheet logic referred to in Section 2. That is, a vortex line (of constant strength for the hover case) can be inserted into the grid by specifying a surface across which there is a potential discontinuity whose magnitude equals the desired vortex strength. The edge of this sheet is the desired vortex line. For a constant-strength vortex the sheet is merely a branch cut and its orientation should have no effect on the solution. Such a vortex is shown in Fig. 1 , represented by a vertical sheet.

Hover flight is a good case to test the approach described previously because the vortex strength is constant. Furthermore, the vortex geometry is fairly simple and can be reasonably represented by straight lines parallel to the flow in the near-blade region. For present purposes, a number of steady 
finite difference computations have been made of hover flows using the relaxation code of Ref. [4]. In the current computations, two vortices (represented by vertically oriented sheets) are located beneath the blade. However, this does not yet account for the total effect of the entire wake system. We assumed therefore that the more distant elements of the wake system can be accounted for by a modified angle of attack. The modification consists of computing the angle of attack (using the Biot-Savart law) only from those elements of the wake system not contained in the finite difference grid. Figure 11 shows the computed load distribut:ions on hypothetical twisted and untwisted methods. The FDM results are compared with those of the lifting-surface code, HOVER, described in Ref. [8]. Both codes use the identical far-wake model [8] and assume the vortex strength to equal the maximum blade-bound vorticity. The comparison of the two methods is quite close. The differences that do exist could stem from a number of causes including vortex curvature and boundary conditions.

There also exists a convenient body of experimental data [9] by which to test the previously mentioned wake treatment. This data consists of extensive surface pressure distributions and vortex geometry measurements for a high-speed hovering rotor (untwisted blade, NACA $0012, \mathbb{R}=6.0$ ). The vortex and blade geometry is the only required input for computing the rotor flow. A comparison of the experimental lift distribution with the finite difference and liftingsurface methods is shown in Fig. 12. At this rotor speed $\left(M_{T}=0.6\right)$, the lifting-surface and finite difference results compare closely. However, there is a greater difference near the tip than occurs in the previous high aspect-ratio results. This is almost certainly a result of there being no wake curvature in the finite difference grid. Both the finite difference and lifting-surface results overestimate the maximum lift. Overall, however, the comparison with the data is good. Also included in Fig. 12 is a finite difference computation using only an angle-of-attack boundary condition. For this computation the angle of attack was obtained from momentum theory. It is not surprising to find that the resulting lift is seriously in error at the tip, due to the lack of discrete blade effects in the momentum model. However, the inboard results are good for this case. This indicates that such a simple downwash model may be generally useful for specifying the inboard flow regions.

The comparison of lifting surface, FDM results, and experiment is especially interesting at high tip speeds. Figure 13 shows such a comparison at a tip speed of $M_{T}=0.877$. Since the lifting-surface method is linear (as are almost all integral methods) it is not surprising that this method greatly overestimates the lift in the tip region. However, the FDM computations compare well with the experimental lift distribution. Figure 13 also shows a comparison of the measured pressure distributions with FDM results. The comparisons are favorable even to the extent of properly predicting the correct shock locations. This is a little surprising when one considers that the computed pressure perturbations exceed the assumed limits for small perturbation theory. Indeed, the inaccuracies seen in the leading-edge region undoubtedly stem from small disturbance errors. In addition, no boundary layer corrections have been made.

All operational helicopters operate at low enough tip speeds that linear integral methods will always suffice for hover work. However, in demonstrating the ability to easily duplicate integral results by FDM and to effectively apply these to high speed, we will have performed an essential validation in preparation for general forward-flight computations. 


\section{Vortex-Induced Effect in Forward Flight.}

The extension of the previous mode of vortex representation to unsteady cases has geometrical, numerical, and practical problems associated with it. To begin, the wake for these cases can no longer be represented by a straight, unmoving vortex of constant strength. The sheet defining the vortex system is now a physically real vorticity sheet (for a tip vortex of varying strength) and cannot be given the arbitrary treatment of the hover cases. The tip vortex assumes a wide range of orientations with respect to the blade and can be nearly parallel to it in certain encounters. Clearly, a general forward-flight flow treatment requires the fully unsteady form of $\mathrm{Eq}$. (1). Although there are methods to solve the fully unsteady Eq. (1), there have not yet been many experiments performed to verify these methods. A considerable problem is that there currently exists little usable wake and loading data by which to evaluate new forward-flight methods at the lower advance ratios (say, below 0.3). Therefore, at present the best approach for computation work is to calculate model problems which contain the qualitative effects of blade/vortex interactions in the simplest possible way.

One such model is the two-dimensional interaction of an airfoil with a moving vortex. This model is particularly easy to implement because the vortex can (as in the hover case) be represented by an arbitrarily oriented sheet across which a potential discontinuity is specified (Fig. 14). The edge of the sheet (the vortex) is currently stepped through the grid in a straight line at the speed of the undisturbed free-stream velocity. The strength of the vortex is given as an effective lift coefficient, $\mathrm{C}_{\mathrm{LV}}$, of an airfoil having the same circulation as the vortex. The technique for solving the fully unsteady Eq. in its two-dimensional form is a simple ADI scheme given in Ref. [10]. The effect of unsteadiness in these computations is shown in Fig. 15, which compares blade surface pressure distributions for a fixed and moving vortex. These distributions are shown when the vortex is at the leading-edge, mid-chord, and trailing-edge chordwise locations and at 0.96 chords below the blade $\left(\mathrm{C}_{\mathrm{LV}}=0.1\right)$. Although the steady case clearly shows the effect of the vorticity there is no apparent disturbance for the unsteady case. This result undoubtedly reflects the fact that the vortex exerts no net force on the fluid in the unsteady case. In fact, in order to get a sizable unsteady effect on the surface pressures when the vortex is beneath the profile, it is necessary to bring the vortex much closer to the blade and increase its strength. Figure 16 shows the lift variation for a blade with a vortex of strength $\mathrm{C}_{\mathrm{LV}}=0.4$ whose path is 0.26 chords beneath the blade. As the vortex passes beneath the blade it is seen to significantly enlarge and strengthen the supercritical flow region on the bottom surface. However, the effect quickly disappears after the vortex has passed the shock. It should be recognized that this latter computation could contain a serious error because it does not currently allow the vortex to follow the flow (which varies greatly from the free stream close to the airfoil). This error should cause an exaggeration of the effect of the vortex on the airfoil loads. It seems likely therefore that these close high-frequency interactions will have a far smaller effect on the loads than quasi-steady theory would indicate. This does not say, however, that the effect will be unimportant. The determination of the magnitude of this blade-vortex interaction must await a good experiment and more detailed theoretical modeling.

\section{Concluding Remarks}

The increasing availability of good FDM rotor codes and cheaper computers will ultimately enable the routine simulation of the nonlinear unsteady 
three-dimensional flow about rotors. Initially, these simulations will be isolated blade computations whose specified boundary conditions account for the effect of the wake and interference effects. This paper demonstrates two approaches to the treatment of boundary conditions which result in realistic FDM computations of both hover and high advance-ratio $(\mu>0.3)$ rotor flows. For the latter case (computed with a low-frequency unsteady code) discrete vortex effects are specified as an angle-of-attack variation. The inflow model is very simple and can be improved, although good comparisons with data have been obtained. Even better comparisons have been made for high-speed hover computations (using a steady code). However, for this case it is necessary to use a more exact boundary condition by actually inserting some of the tip vortices into the finite difference grid. In addition, a modified angle of attack (computed from those wake elements not included in the grid) is also required. For the low-to-intermediate range of advance ratios, the problem is more difficult because the wake has a complicated structure which cannot be ignored. Nevertheless, demonstration computations (using a fully unsteady code) have been made on a two-dimensional blade/vortex interaction problem which contains the basic numerical (if not all the geometrical) features of the problem.

The numerical techniques used in this paper are not new but they have not yet seen the full realization of their capabilities for rotor loads, performance prediction, and design work. The hover and high simulations performed in this paper may be the first truly realistic FDM rotor simulations. There seems to be little technical reason for reticence in the use of FDM techniques and we trust that the economic reasons will rapidly diminish.

\section{REFERENCES}

1. M. P. Isom, Unsteady Subsonic and Transonic Potential Flow over Helicopter Rotor Blades, NASA CR-2463, Oct. 1974.

2. F. X. Caradonna and J. J. Philippe, The Flow over a Helicopter Blade Tip in the Transonic Regime, Vertica, Vo1. 2, 1978, pp. 43-60.

3. J. J. Philippe and J. J. Chattot, Experimental and Theoretical Studies on Helicopter Blade Tips at ONERA, Presented at the Sixth European Rotorcraft and Powered Lift Aircraft Forum, Bristol, U.K., Paper No. 46, Sept. 1980, pp. 16-19.

4. F. X. Caradonna, The Transonic Flow on a Helicopter Rotor, Ph.D. Dissertation, Stanford University, Mar. 1978.

5. B. Monnerie and J. J. Philippe, Aerodynamic Problems of Helicopter Blade Tips, Vertica, Vol. 2, pp. 217-231.

6. J. M. Drees, A Theory of Airflow Through Rotors and Its Application to some Helicopter Problems, Journal of the Helicopter Association of Great Britain, Vo1. 2, 1949.

7. A. Desopper and R. Grenon, Couplage fluide parfait-fluide visqueux en ecoulement instationaire bidimensionnel incompressible et transsonique, Computation of Viscous-Inviscid Interactions, AGARD CP-291, 1980.

8. J. M. Summa and D. R. Clark, A Lifting-Surface Method for Hover/Climb Loads, Presented at the 35th Annual Forum of the American Helicopter Society, Washington, D.C., Preprint 79-1, May 1979. 
9. F. X. Caradonna and C. Tung, Experimental and Analytical Studies of a Model Helicopter Rotor in Hover, NASA TM-81232, Sept. 1981.

10. F. X. Caradonna and J. L. Steger, "Implicit Potential Methods for the Solution of Transonic Rotor Flows, Proceedings of the 1980 Army Numerical Analysis and Computers Conference, Army Research Office Report 80-3. 


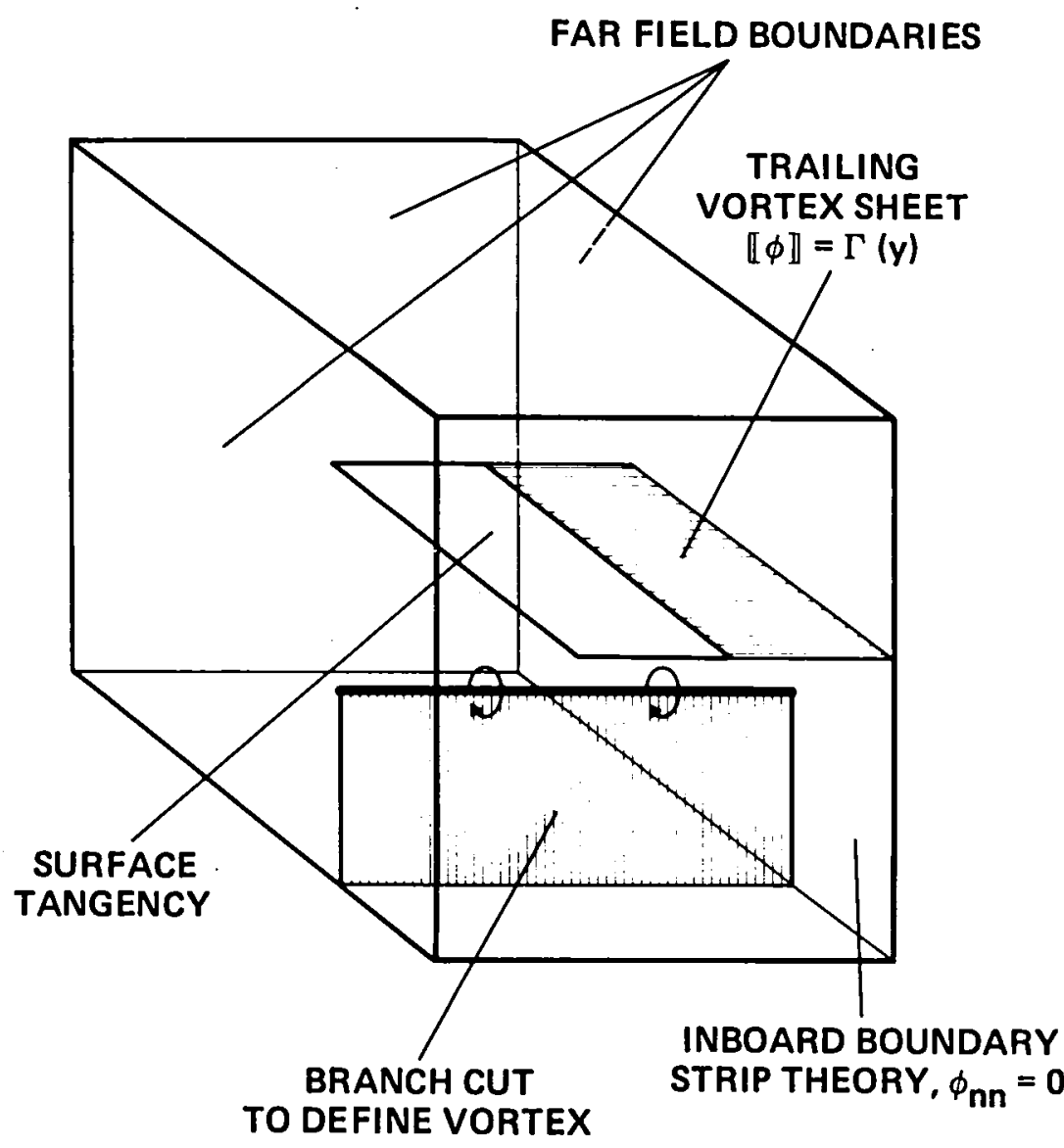

Fig. 1. Boundary conditions for the rotor potential flow problem. 


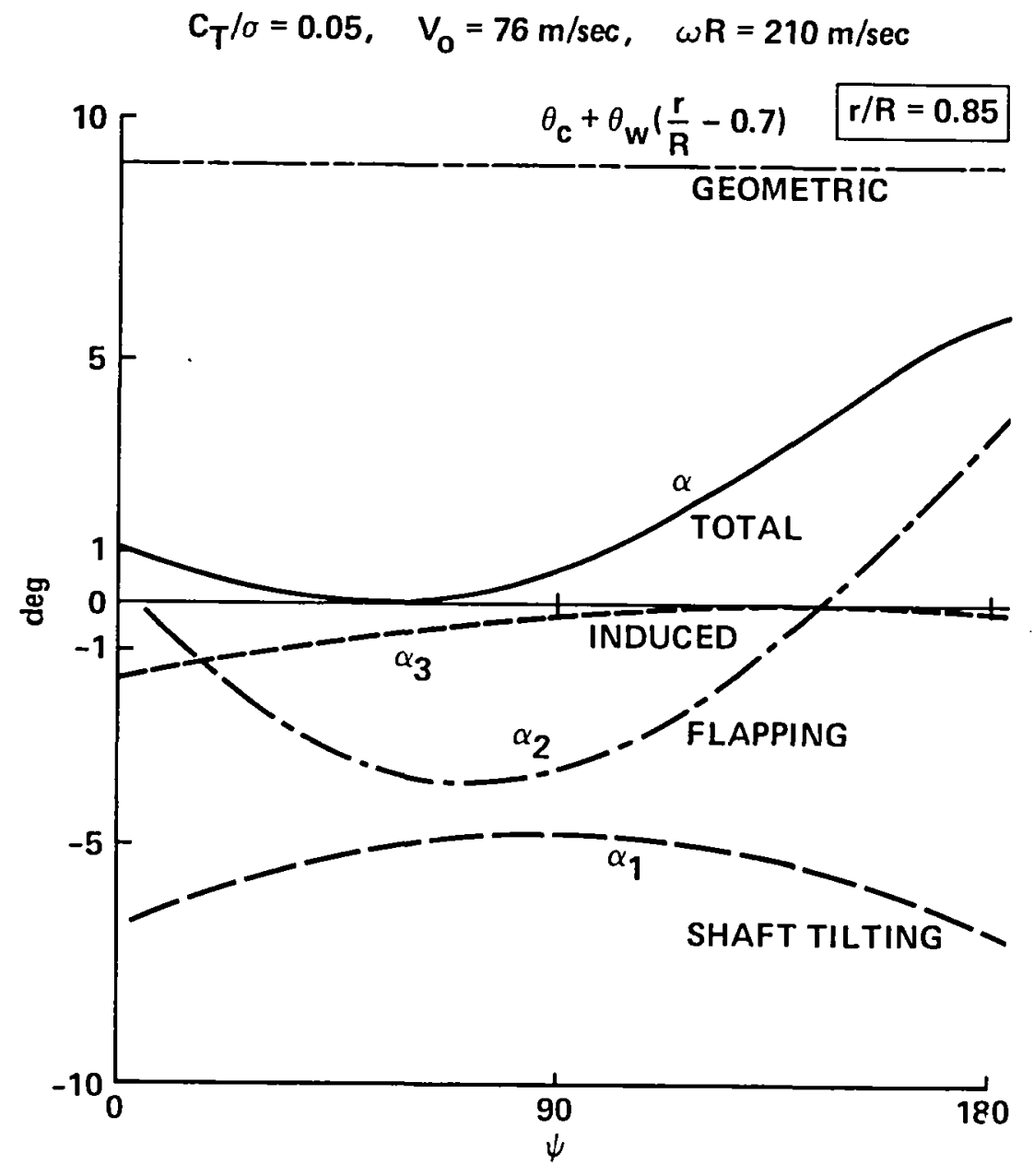

Fig. 2. Total angle of incidence calculated by Drees downwash model. 
$C_{T} / \sigma=0.05, \quad V_{0}=76 \mathrm{~m} / \mathrm{sec}, \quad \omega R=210 \mathrm{~m} / \mathrm{sec}$

- UPPER SURFACE $\}$ CALCULATION
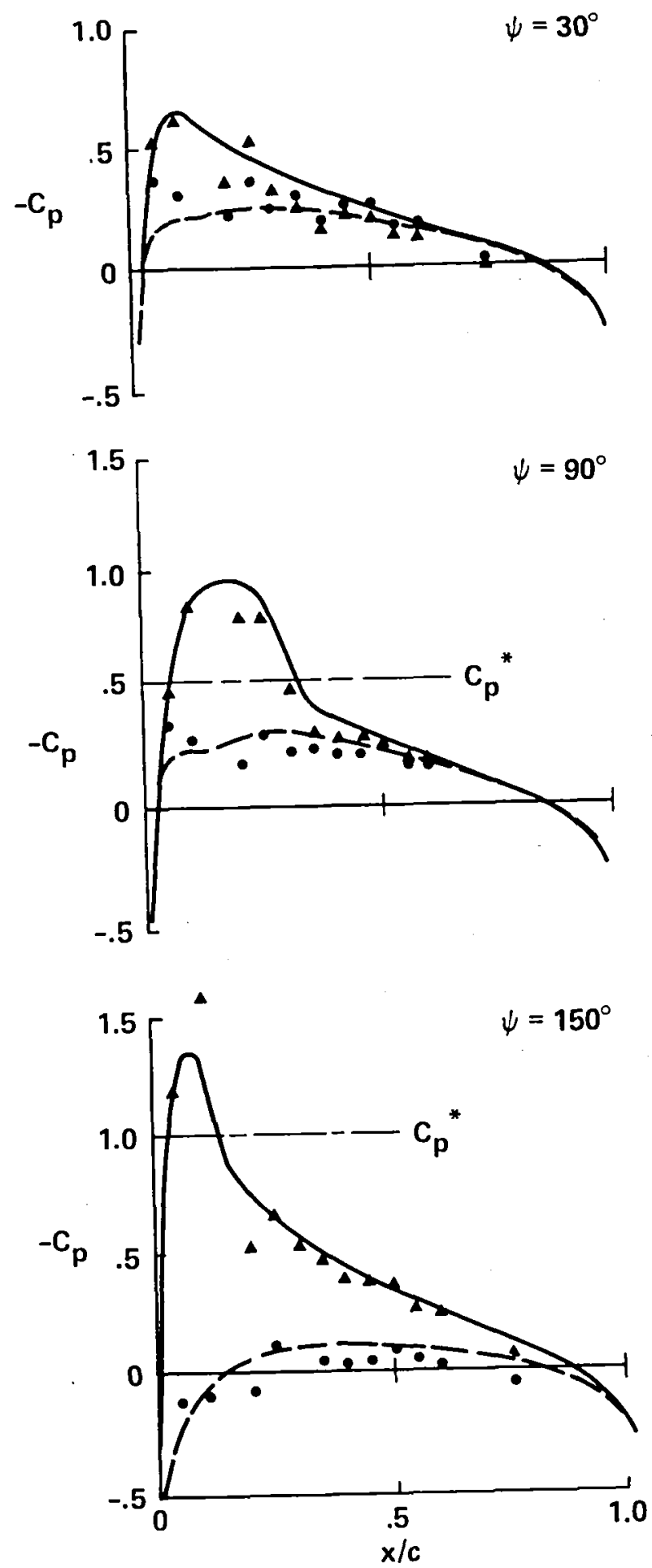

$\left.\begin{array}{l}\text { - UPPER SURFACE } \\ \text { - LOWER SURFACE }\end{array}\right\}$ EXPERIMENT
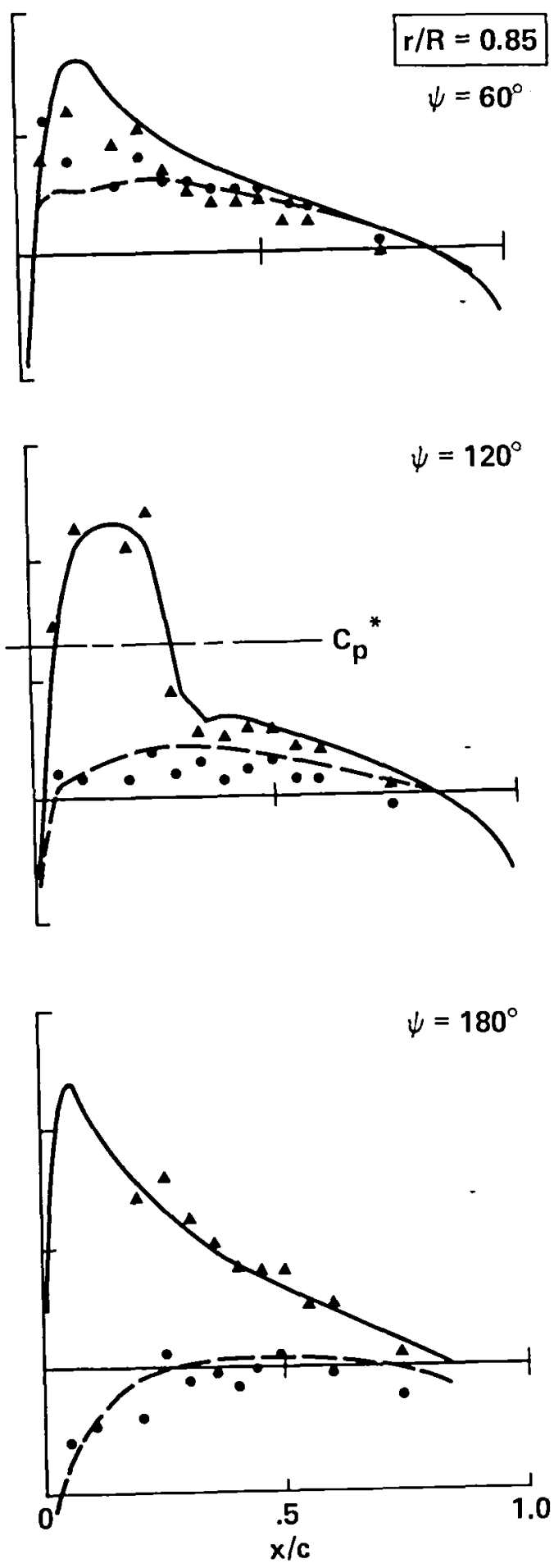

Fig. 3. Comparison of measured and computed chordwise pressure distribution at different azimuthal angles, $\mathrm{C}_{\mathrm{T}} / \sigma=0.05, \mathrm{r} / \mathrm{R}=0.85$. 
$C_{T} / \sigma=0.05, \quad V_{0}=76 \mathrm{~m} / \mathrm{sec}, \quad \omega R=210 \mathrm{~m} / \mathrm{sec}$

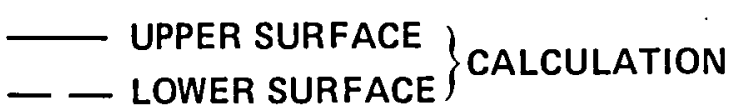

$\left.\begin{array}{l}\text { - UPPER SURFACE } \\ \text { - LOWER SURFACE }\end{array}\right\}$ EXPERIMENT
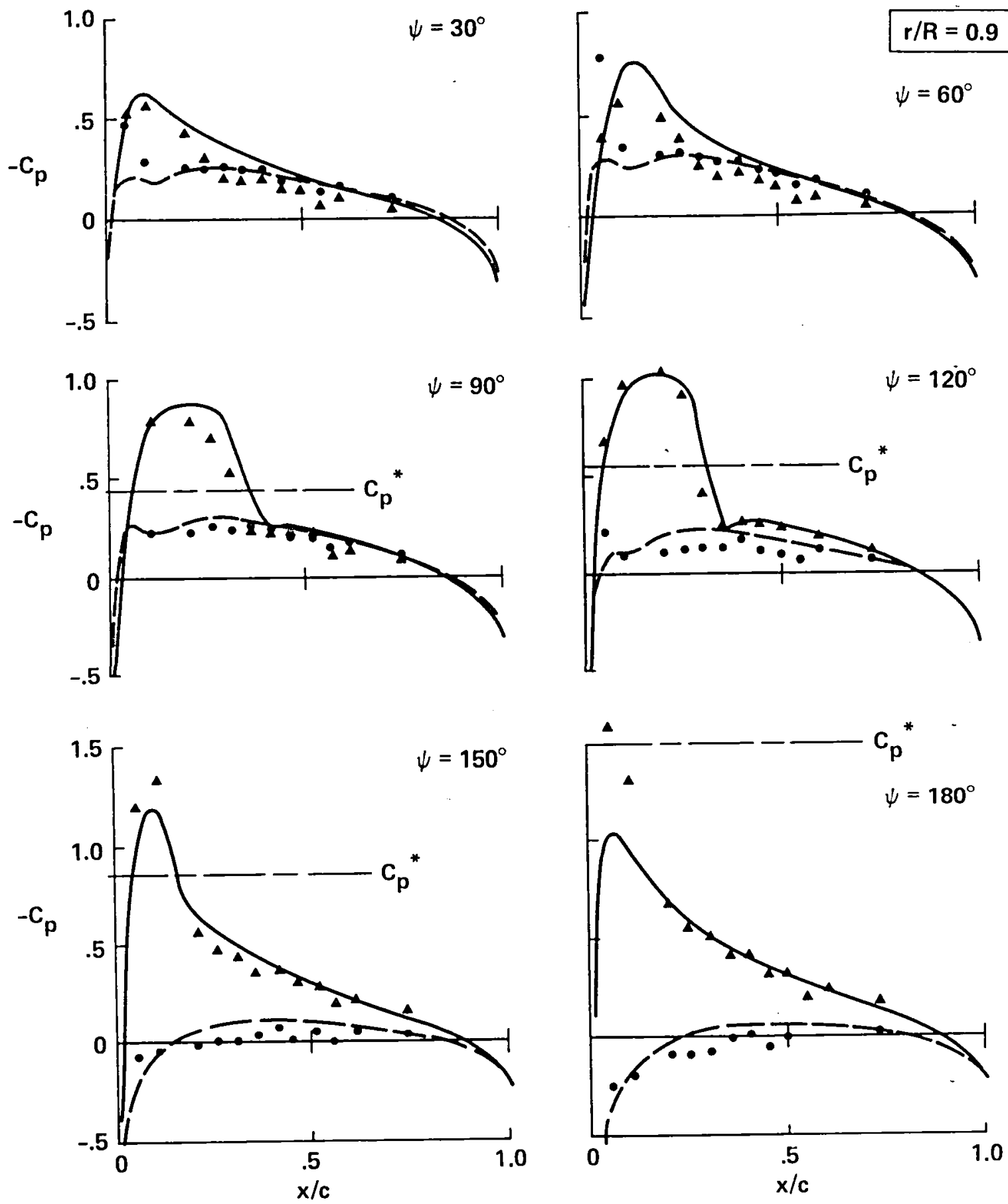

Fig. 4. Comparison of measured and computed chordwise pressure distribution at different azimuthal angles, $\mathrm{C}_{\mathrm{T}} / \sigma=0.05, \mathrm{r} / \mathrm{R}=0.90$. 
$C_{T} / \sigma=0.05, \quad V_{o}=76 \mathrm{~m} / \mathrm{sec}, \quad \omega R=210 \mathrm{~m} / \mathrm{sec}$

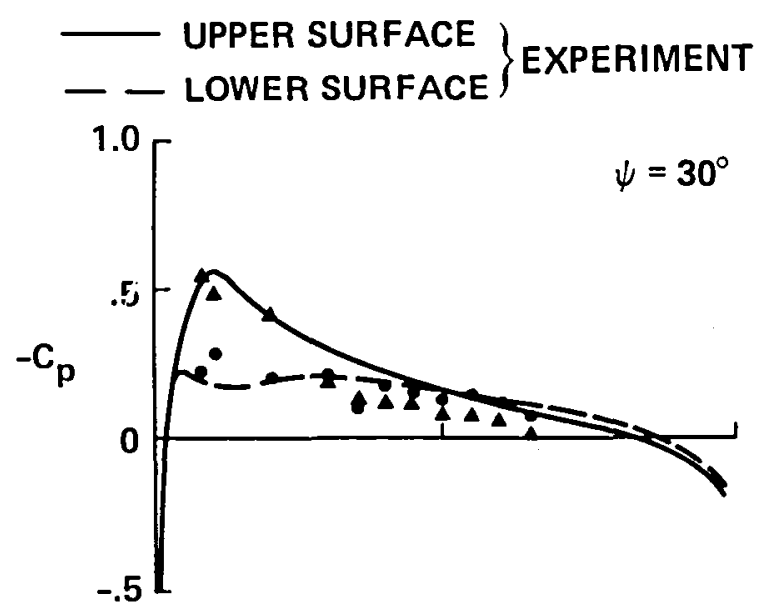

$\left.\begin{array}{l}\text { - UPPER SURFACE } \\ \text { - LOWER SURFACE }\end{array}\right\}$ CALCULATION
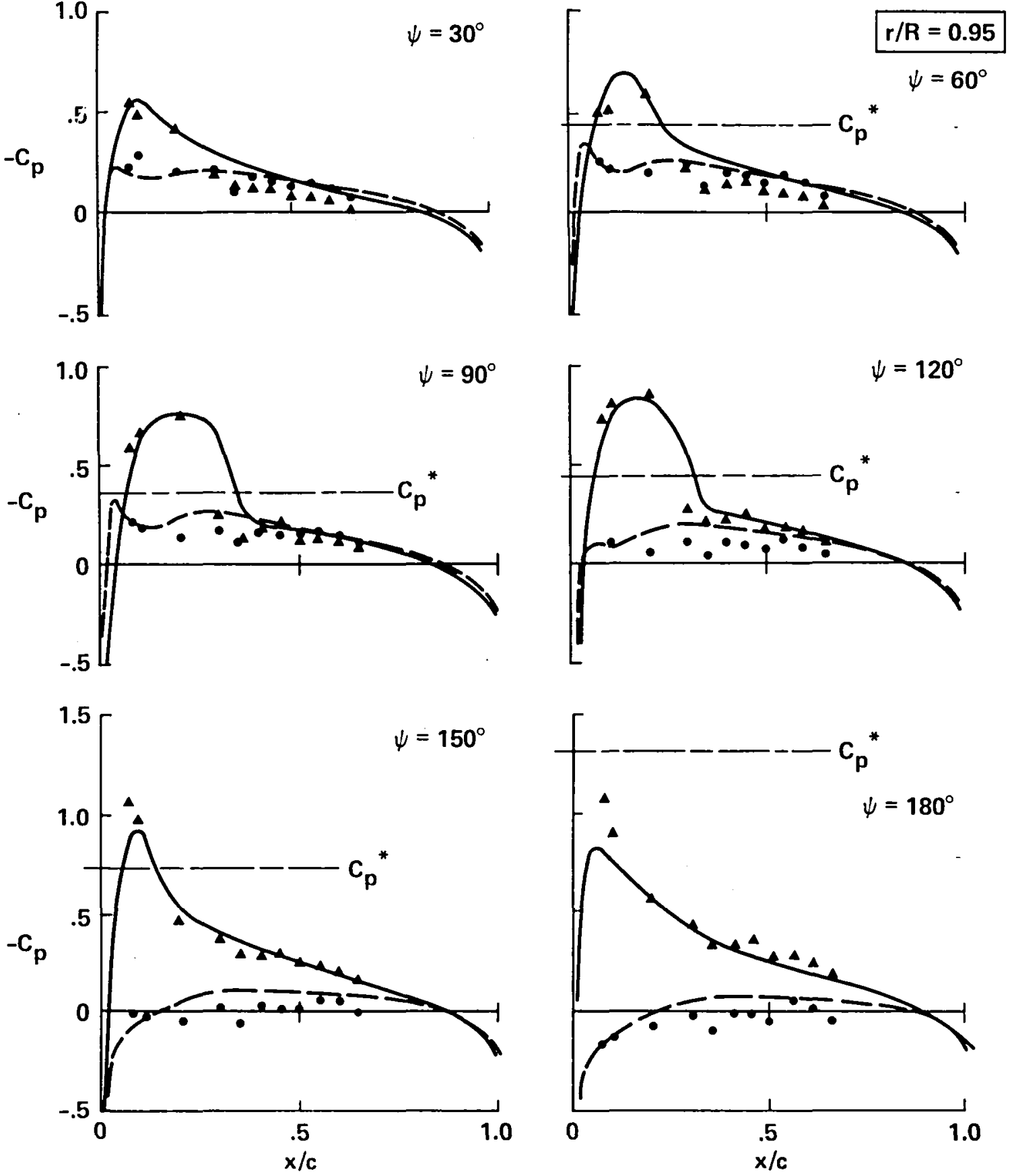

Fig. 5. Comparison of measured and computed chordwise pressure distribution at different azimuthal angles, $\mathrm{C}_{\mathrm{T}} / \sigma=0.05, \mathrm{r} / \mathrm{R}=0.95$. 


$$
\mathrm{C}_{\mathrm{T}} / \sigma=0.0665, \quad \mathrm{~V}_{\mathrm{o}}=81.4 \mathrm{~m} / \mathrm{sec}, \quad \omega \mathrm{R}=210 \mathrm{~m} / \mathrm{sec}
$$
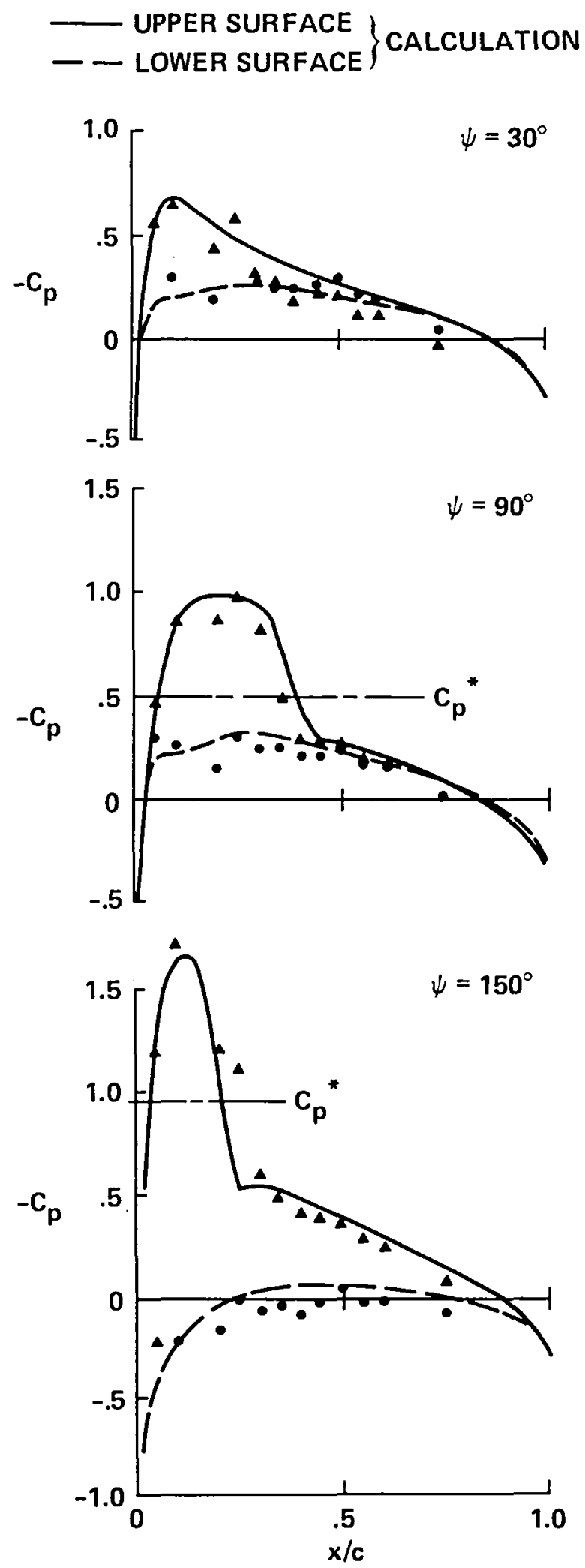

$\left.\begin{array}{l}\text { - UPPER SURFACE } \\ \text { - LOWER SURFACE }\end{array}\right\}$ EXPERIMENT
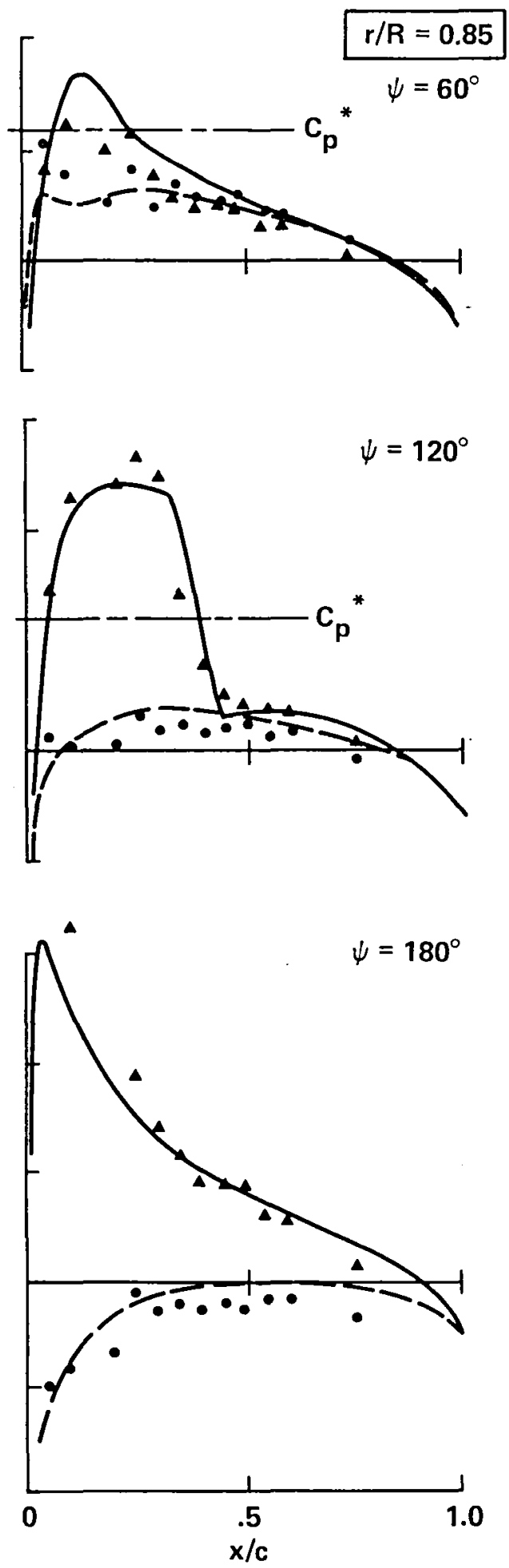

Fig. 6. Comparison of measured and computed chordwise pressure distribution at different azimuthal angles, $C_{T} / \sigma=0.0665, r / R=0.85$. 


$$
C_{T} / \sigma=0.0665, \quad V_{0}=81.4 \mathrm{~m} / \mathrm{sec}, \quad \omega R=210 \mathrm{~m} / \mathrm{sec}
$$

UPPER SURFACE $\}$ CALCULATION
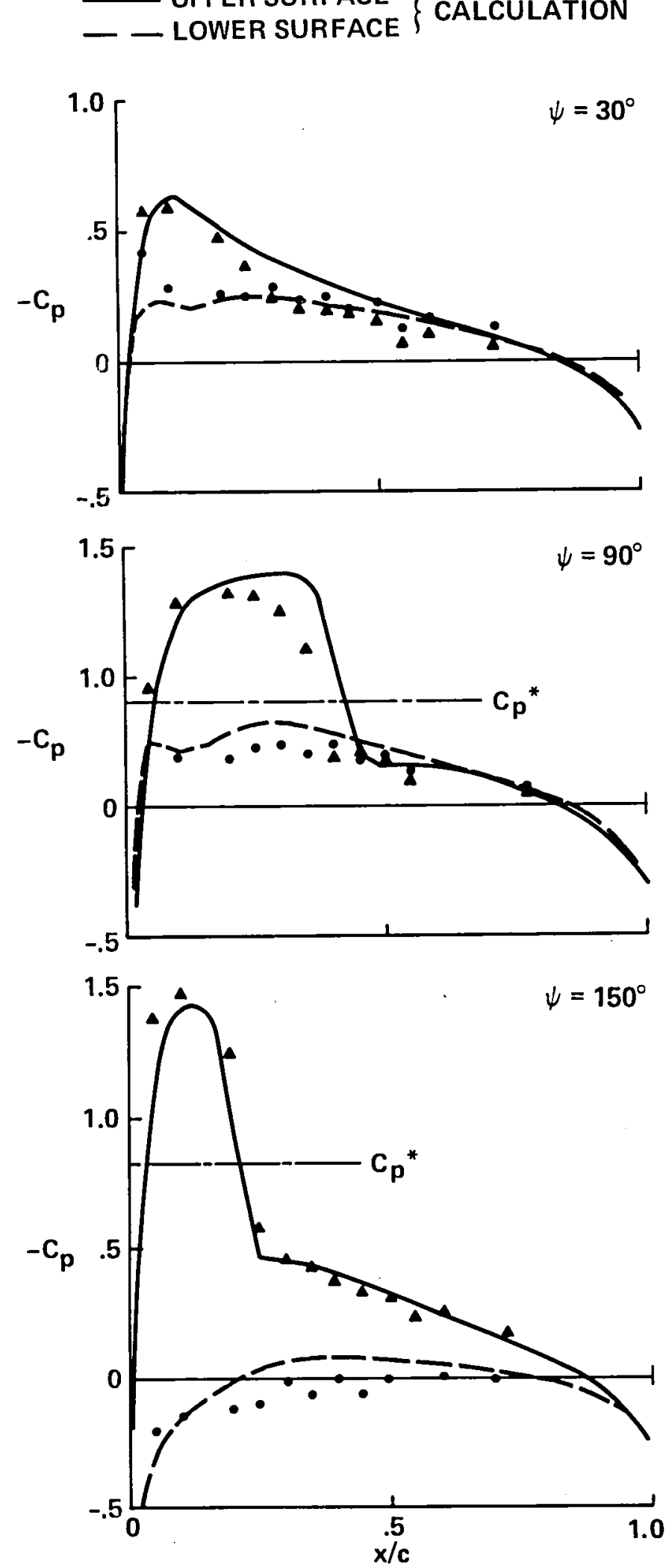

$\left.\begin{array}{l}\text { - UPPER SURFACE } \\ \text { - LOWER SURFACE }\end{array}\right\}$ EXPERIMENT
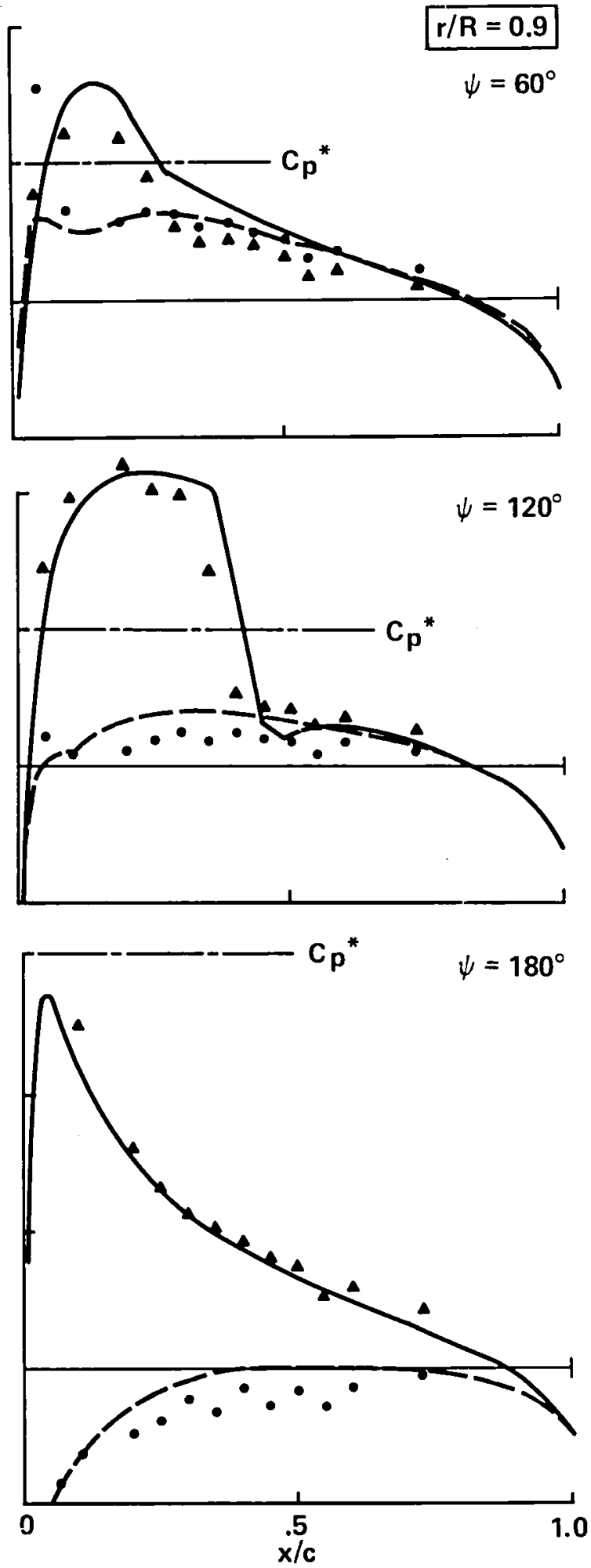

Fig. 7. Comparison of measured and computed chordwise pressure distribution at different azimuthal angles, $\mathrm{C}_{\mathrm{T}} / \sigma=0.0665, \mathrm{r} / \mathrm{R}=0.90$. 


$$
\mathrm{C}_{\mathrm{T}} / \sigma=0.0665, \quad \mathrm{~V}_{\mathrm{o}}=81.4 \mathrm{~m} / \mathrm{sec}, \quad \omega \mathrm{R}=210 \mathrm{~m} / \mathrm{sec}
$$
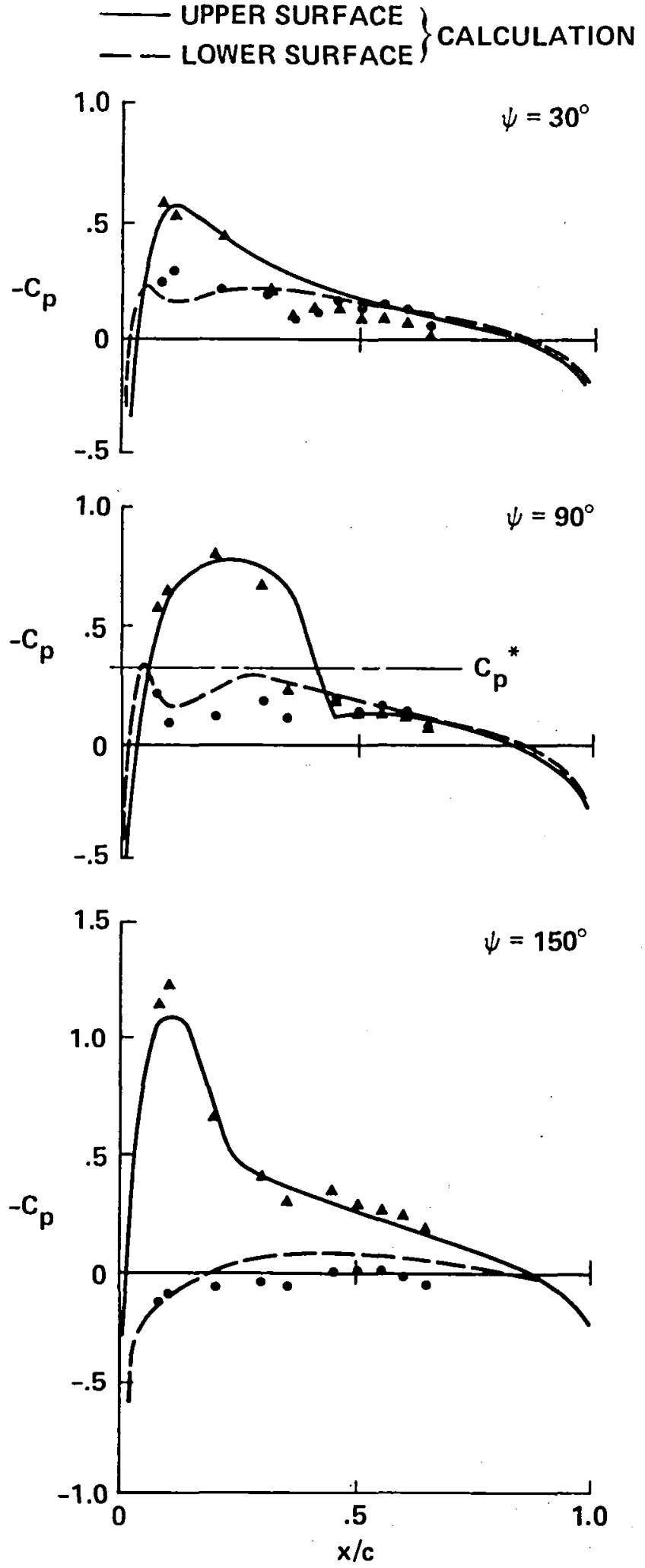

$\left.\begin{array}{l}\text { - UPPER SURFACE } \\ \text { - LOWER SURFACE }\end{array}\right\}$ EXPERIMENT
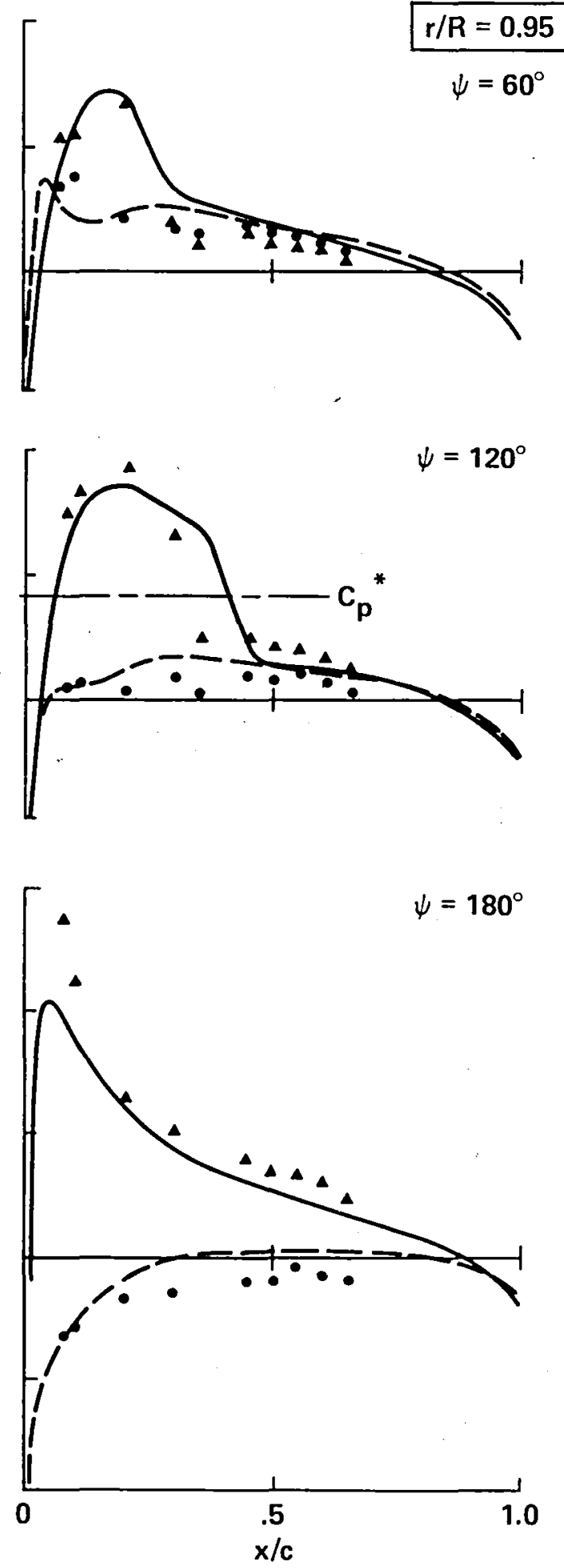

Fig. 8. Comparison of measured and computed chordwise pressure distribution at different azimuthal angles, $\mathrm{C}_{\mathrm{T}} / \sigma=0.0665, \mathrm{r} / \mathrm{R}=0.95$. 

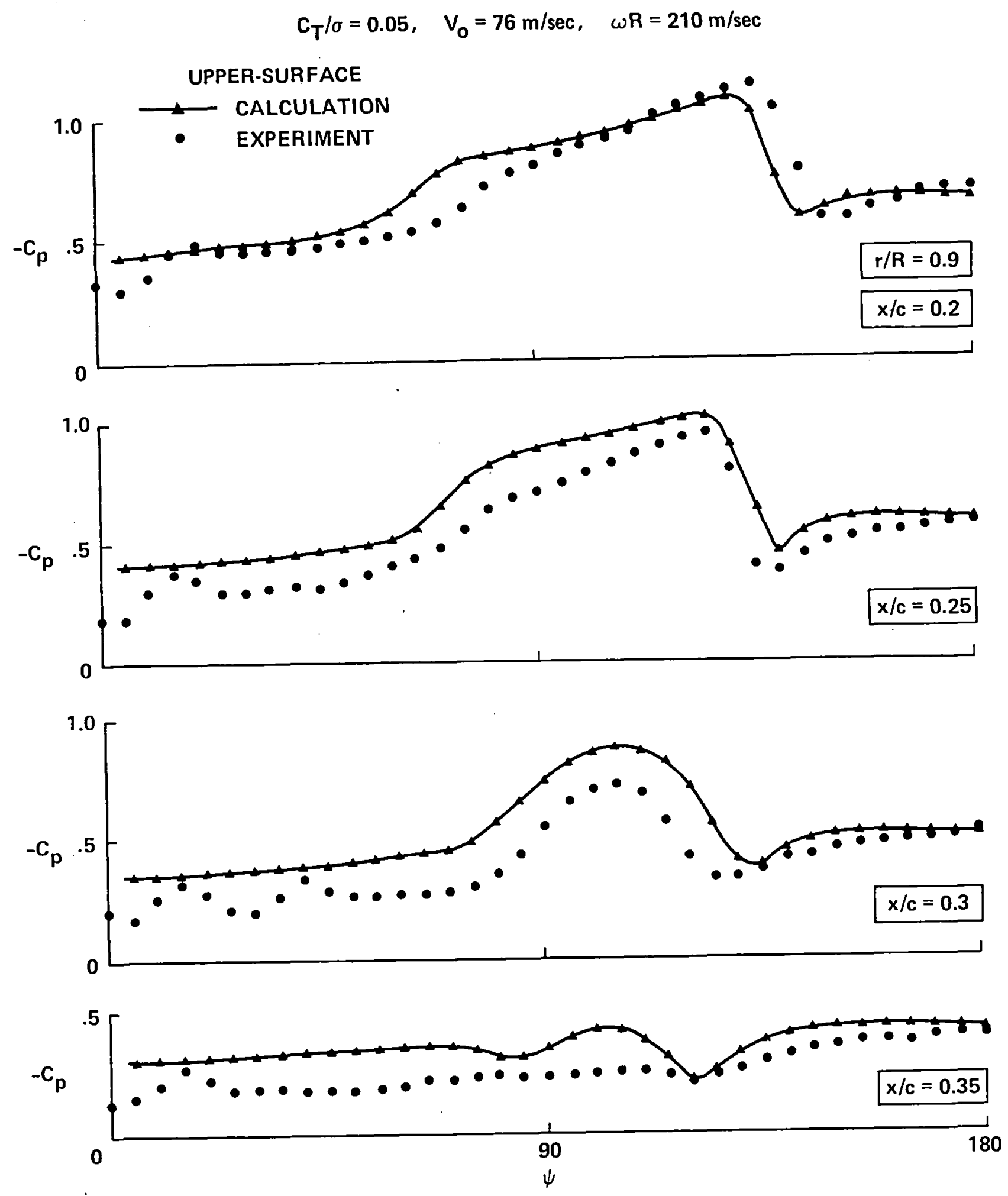

Fig. 9 Comparison of measured and computed pressure coefficient at different chordwise stations, $\mathrm{C}_{\mathrm{T}} / \sigma=0.05, \mathrm{r} / \mathrm{R}=0.90$. 

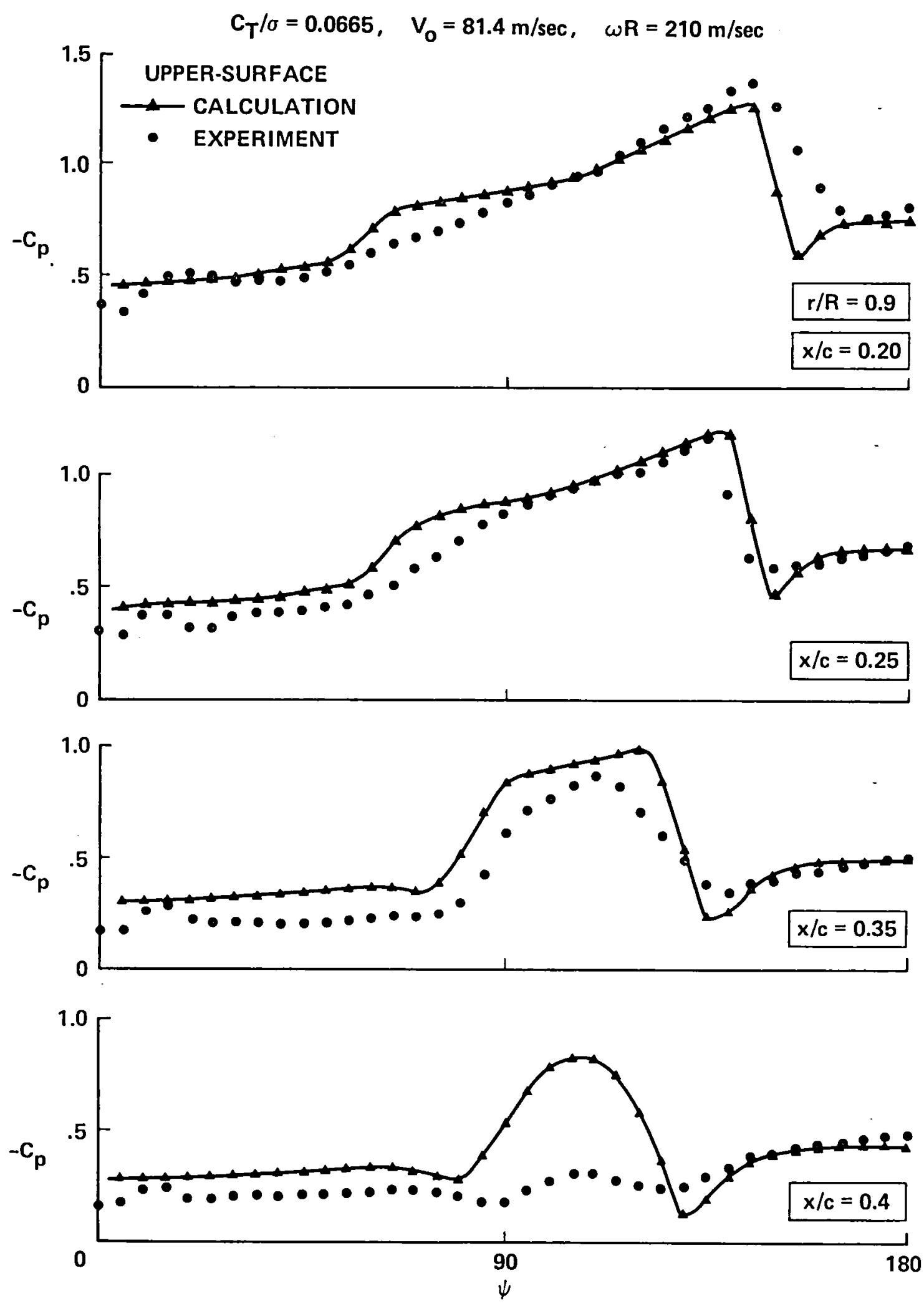

Fig. 10. Comparison of measured and computed pressure coefficient at different chordwise stations, $\mathrm{C}_{\mathrm{T}} / \sigma=0.0665, \mathrm{r} / \mathrm{R}=0.9$. 

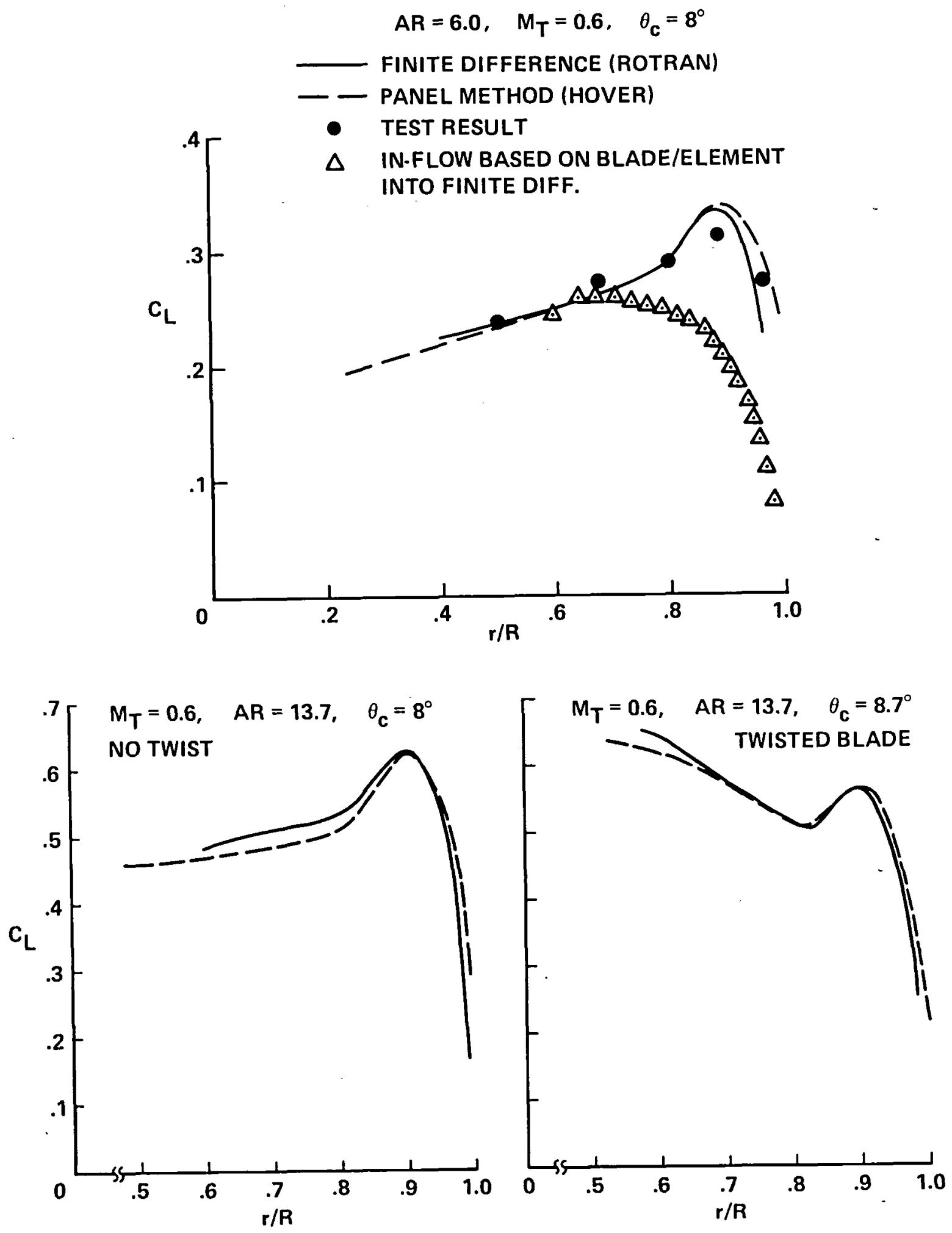

Fig. 11. Comparison of computed loadings by panel and finite difference method. 


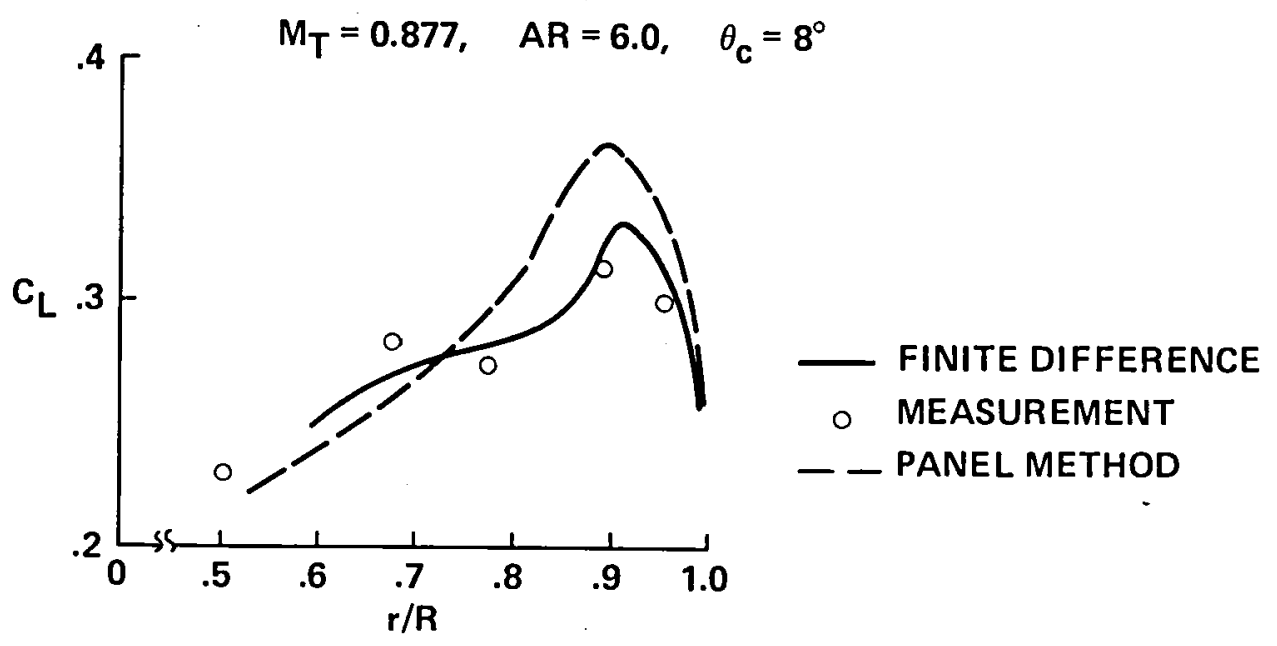

$\left.\begin{array}{ll}- \text { UPPER SURFACE } \\ - \text { - LOWER SURFACE }\end{array}\right\} \begin{aligned} & \text { FINITE } \\ & \text { DIFFERENCE }\end{aligned}$
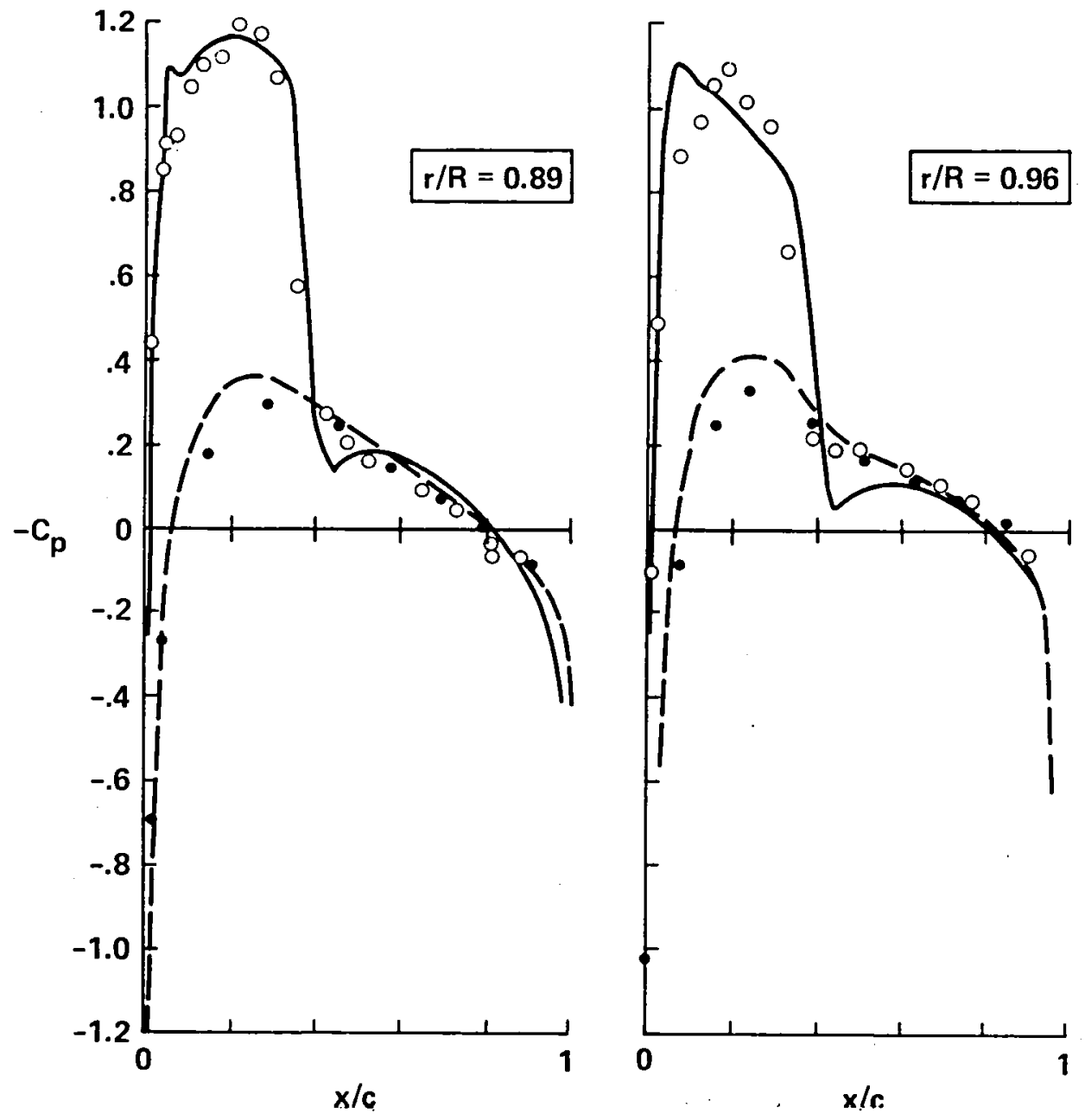

Fig. 12. Comparison of measured and computed chordwise pressure distribution at $\mathrm{M}_{\mathrm{T}}=0.877, \mathrm{r} / \mathrm{R}=0.89$, and $\mathrm{r} / \mathrm{R}=0.96$, respectively. 


$$
M_{T}=0.877, \quad A R=6.0, \quad \theta_{C}=8^{\circ}
$$
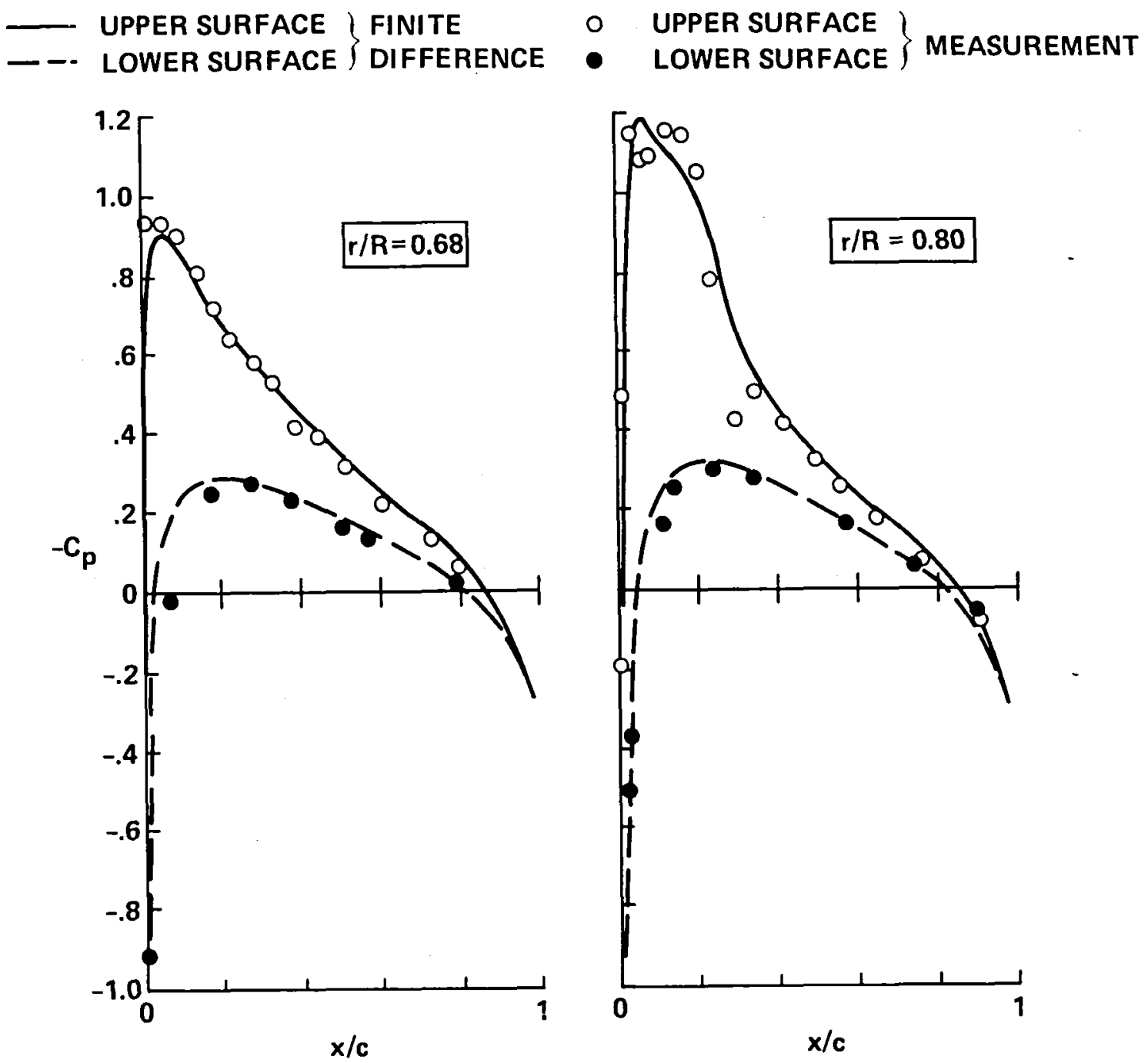

Fig. 13. Comparison of measured and computed chordwise pressure distribution at $M_{T}=0.877, r / R=0.5$, and $r / R-0.68$, respectively. 


\section{SMALL DISTURBANCE BOUNDARY CONDITIONS}

FOR 2-D WING/VORTEX PROBLEM

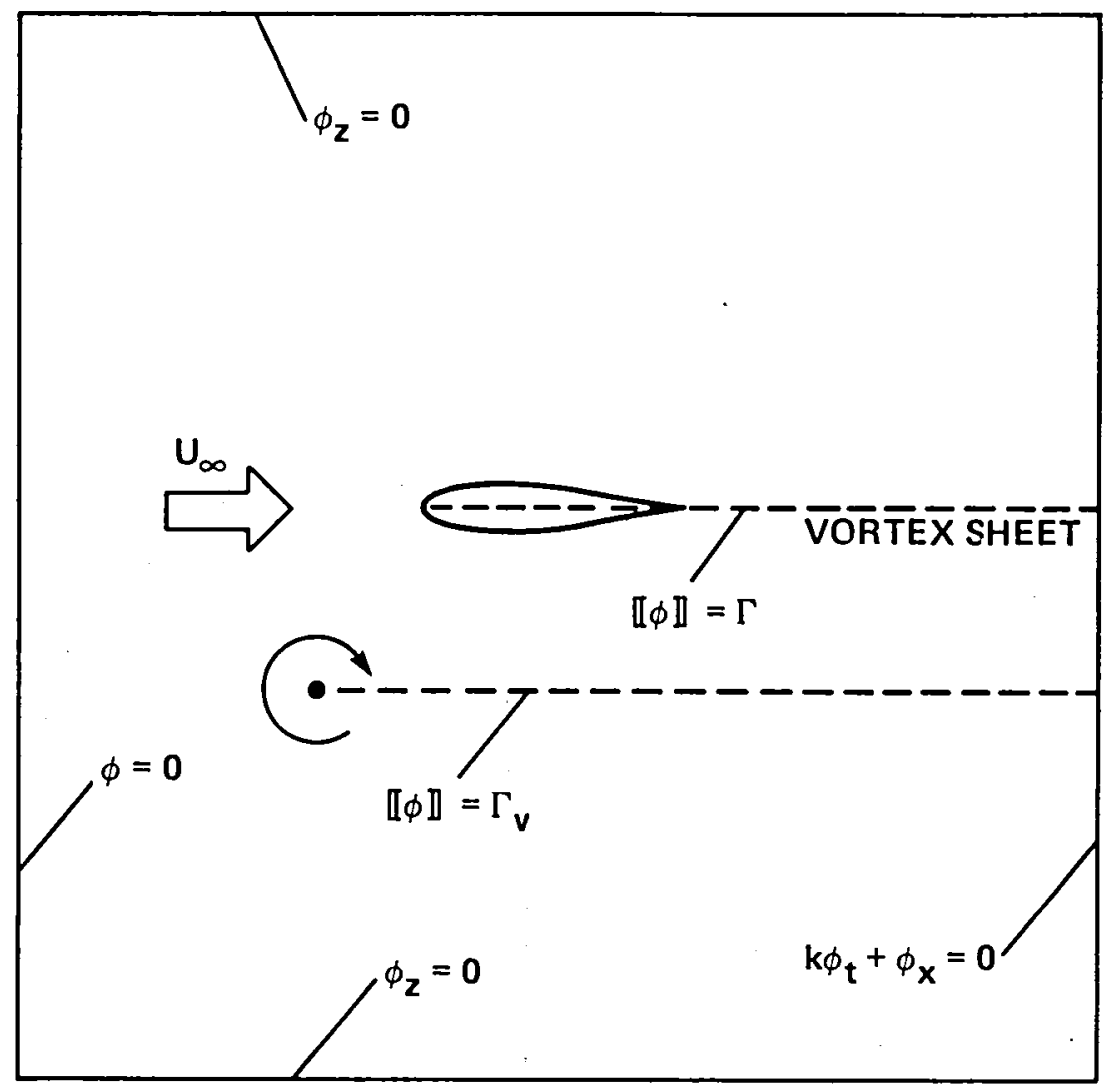

Fig. 14. Boundary conditions for the blade/vortex interaction problem. 


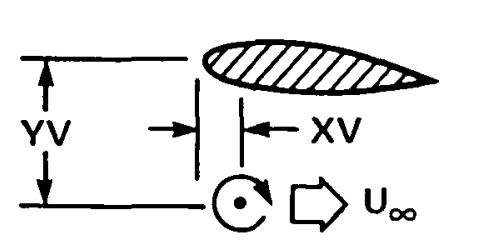

NACA 0012

$0.5^{\circ}$ INCIDENCE

$M_{\infty}=0.8$

VORTEX STRENGTH, $C_{L V}=0.13$

$\mathrm{YV}=0.97$
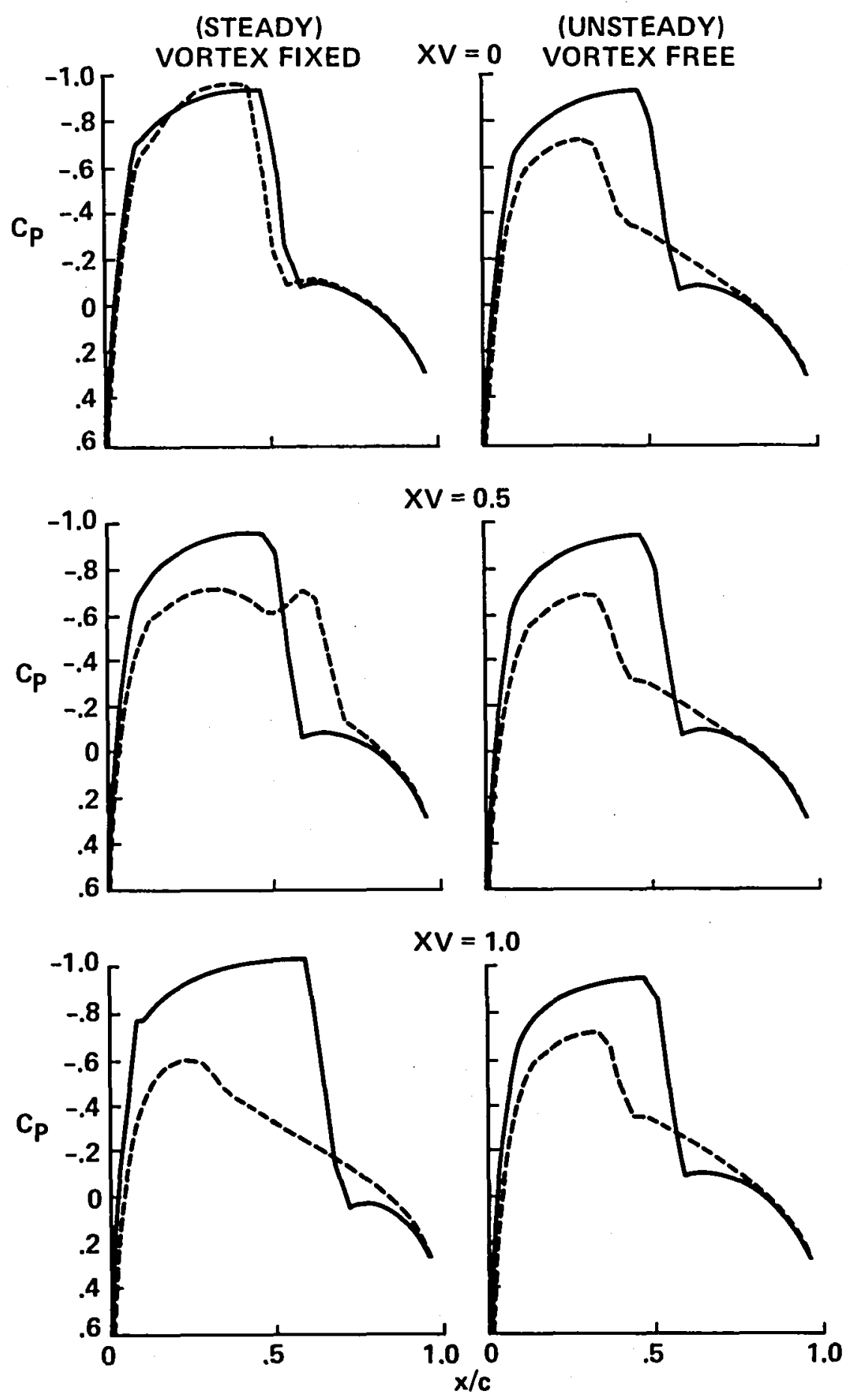

Fig. 15. Steady and unsteady flow computations for the blade/vortex interaction problem. 

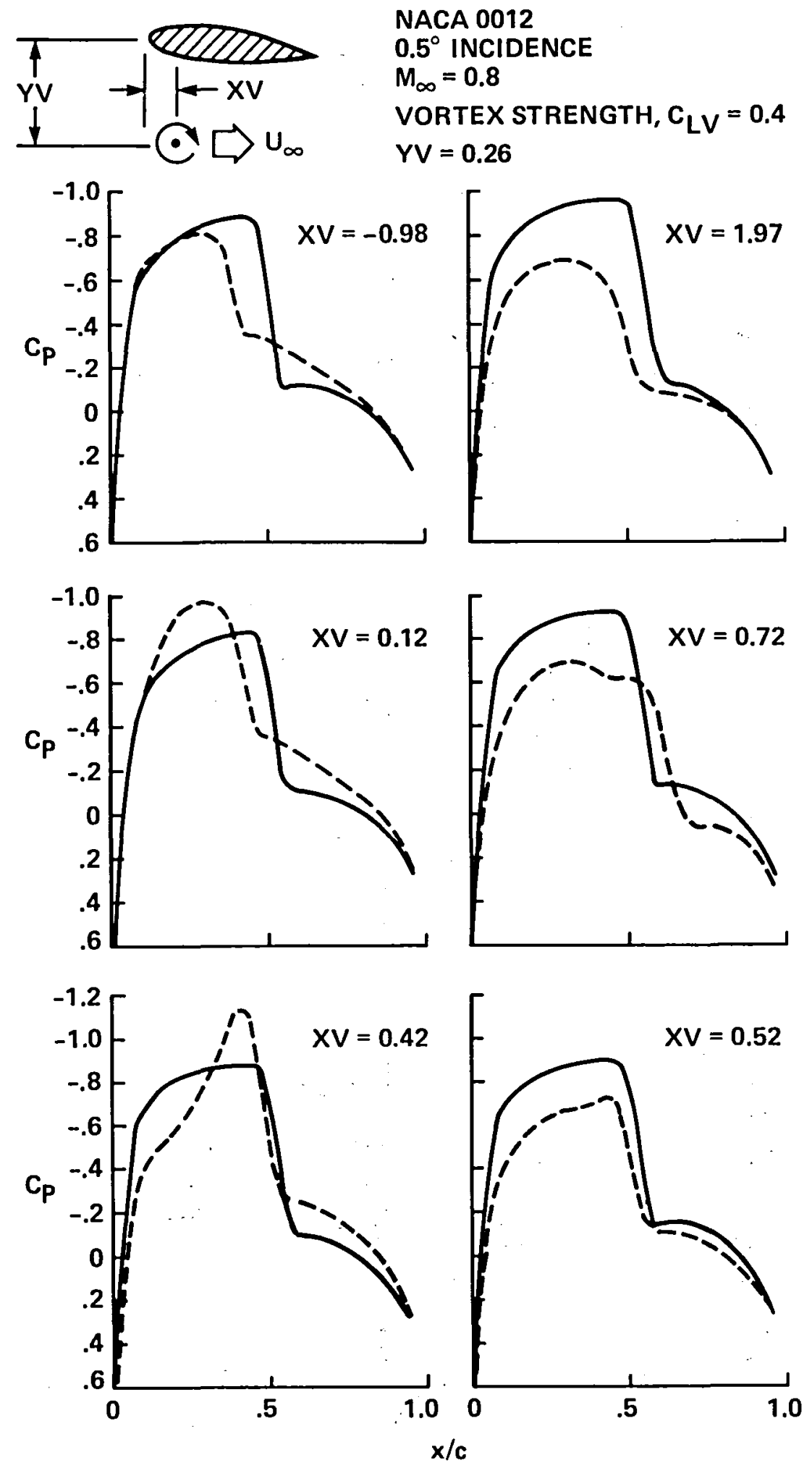

Fig. 16. Unsteady flow computations for the blade/vortex interaction problem. 


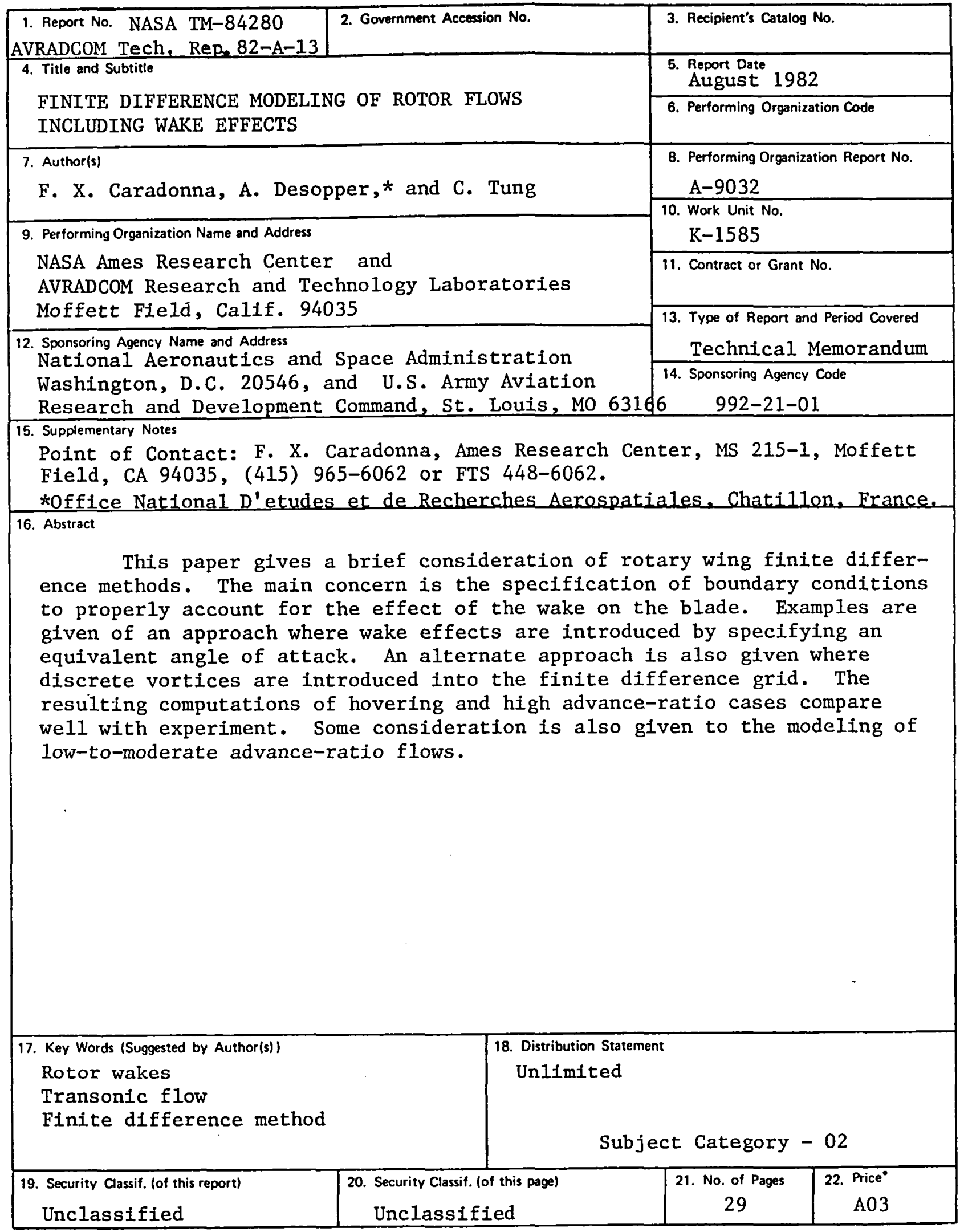

"For sale by the National Technical Information Service, Springfield, Virginia 22161 


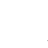



